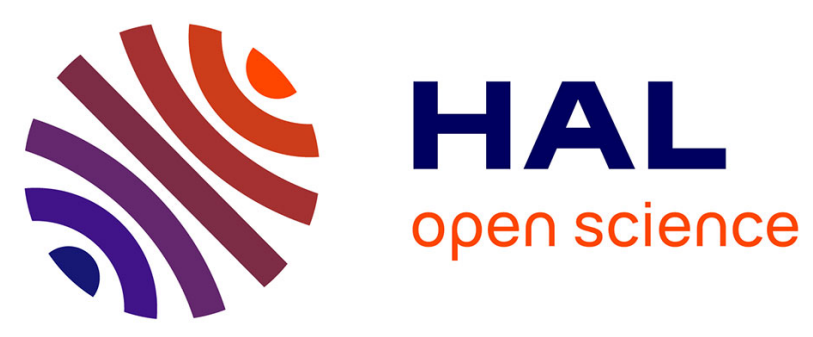

\title{
Quantitative compositional analysis of Martian mafic regions using MEx/OMEGA reflectance data: 1. Methodology, uncertainties and examples of application
}

François Poulet, J.-P. Bibring, Y. Langevin, J.F. Mustard, N. Mangold, M. Vincendon, B. Gondet, P. Pinet, J.-M. Bardintzeff, B. Platevoe

\section{To cite this version:}

François Poulet, J.-P. Bibring, Y. Langevin, J.F. Mustard, N. Mangold, et al.. Quantitative compositional analysis of Martian mafic regions using MEx/OMEGA reflectance data: 1. Methodology, uncertainties and examples of application. Icarus, 2009, 201 (1), pp.69. 10.1016/j.icarus.2008.12.025 . hal-00524854

\section{HAL Id: hal-00524854 \\ https://hal.science/hal-00524854}

Submitted on 9 Oct 2010

HAL is a multi-disciplinary open access archive for the deposit and dissemination of scientific research documents, whether they are published or not. The documents may come from teaching and research institutions in France or abroad, or from public or private research centers.
L'archive ouverte pluridisciplinaire HAL, est destinée au dépôt et à la diffusion de documents scientifiques de niveau recherche, publiés ou non, émanant des établissements d'enseignement et de recherche français ou étrangers, des laboratoires publics ou privés. 


\section{Accepted Manuscript}

Quantitative compositional analysis of Martian mafic regions using MEx/OMEGA reflectance data: 1. Methodology, uncertainties and examples of application

F. Poulet, J.-P. Bibring, Y. Langevin, J.F. Mustard, N. Mangold, M. Vincendon, B. Gondet, P. Pinet, J.-M. Bardintzeff, B. Platevoe

PII: $\quad$ S0019-1035(08)00454-5

DOI: $\quad$ 10.1016/j.icarus.2008.12.025

Reference: $\quad$ YICAR 8864

To appear in: Icarus

Received date: 9 June 2008

Revised date: 4 December 2008

Accepted date: 11 December 2008

Please cite this article as: F. Poulet, J.-P. Bibring, Y. Langevin, J.F. Mustard, N. Mangold, M. Vincendon, B. Gondet, P. Pinet, J.-M. Bardintzeff, B. Platevoe, Quantitative compositional analysis of Martian mafic regions using MEx/OMEGA reflectance data: 1. Methodology, uncertainties and examples of application, Icarus (2009), doi: 10.1016/j.icarus.2008.12.025

This is a PDF file of an unedited manuscript that has been accepted for publication. As a service to our customers we are providing this early version of the manuscript. The manuscript will undergo copyediting, typesetting, and review of the resulting proof before it is published in its final form. Please note that during the production process errors may be discovered which could affect the content, and all legal disclaimers that apply to the journal pertain. 
Quantitative compositional analysis of Martian mafic regions using MEx/OMEGA reflectance data: 1. Methodology, uncertainties and examples of application

F. Poulet ${ }^{1}$, J.-P. Bibring ${ }^{1}$, Y. Langevin ${ }^{1}$, J. F. Mustard ${ }^{2}$, N. Mangold ${ }^{3}$, M. Vincendon ${ }^{1}$, B. Gondet $^{1}$, P. Pinet ${ }^{4}$, J.-M. Bardintzeff ${ }^{3,5}$, B. Platevoet ${ }^{3}$

${ }^{1}$ Institut d'Astrophysique Spatiale, Université Paris-Sud, 91405 Orsay Cedex, France

${ }^{2}$ Department of Geological Sciences, Brown University, Providence, USA

${ }^{3}$ IDES, Bât. 509, Université Paris-Sud, 91405 Orsay Cedex, France

${ }^{4}$ Observatoire Midi-Pyrénées, 31400 Toulouse, France

${ }^{5}$ IUFM, Université de Cergy-Pontoise, RP 815, 78008 Versailles, France 
Proposed running head: Quantitative compositional analysis of Martian mafic regions

Send correspondence to:

François Poulet

Institut d'Astrophysique Spatiale

Bâtiment 121, Université Paris-Sud

91405 Orsay Cedex

France

Phone: +33169858582

Email: francois.poulet@ias.u-psud.fr 


\section{Abstract}

The Mars Express Observatoire pour la Minéralogie, l'Eau, les Glaces et l'Activité (OMEGA) collected an unprecedented visible and near-infrared hyperspectral dataset covering the low albedo regions of Mars. We investigate the ability to infer modal abundance of surfaces of these regions from a radiative transfer model developed by Shkuratov et al. [Shkuratov, Y., Starukhina, L., Hoffmann, H., Arnold G., 1999. Icarus 137, 235-246] and adapted to basaltic surfaces by Poulet and Erard [Poulet F., Erard, S., 2004 J. Geophys. Res. 109(E2)]. From OMEGA measurements of mafic surfaces, we develop several sensitivity tests to assess the extent to which the model can be applied to predict pyroxene composition (high-calcium phase and low-calcium phase), abundance of almost neutral components (plagioclase) in the near-infrared wavelength as well as grain sizes, by using a library of selected end-members. Results of the sensitivity tests indicate that the scattering model can estimate both abundances and grain sizes of major basaltic materials of low albedo regions within uncertainties $(+/-5$ to 15 vol. \%). The model is then applied to data from dissected cratered terrains located in Terra Meridiani. The derived grain size including uncertainties is in the $50-500 \mu \mathrm{m}$ range. This is consistent with the thermal inertia and albedo of this region, which indicates a fine sand-sized surface with little dust. The abundances of plagioclase (43-57\%) and pyroxenes (35-45+/$10 \%$, including $11+/-5 \%$ of low-calcium phase) are in good agreement with previous basaltlike compositions of low albedo regions from thermal infrared spectral measurements. The method presented in this paper will provide a valuable tool for evaluating the modal mineralogy of other mafic regions of Mars observed in the near-infrared wavelength range.

Keywords: Mars, Surface; Mineralogy; Infrared observations; Spectroscopy 


\section{Introduction}

The Observatoire pour la Minéralogie, l'Eau, les Glaces et l'Activité (OMEGA) experiment is designed to study the composition and physical properties of the Martian surface thanks to Visible/Near-InfraRed (VNIR) reflectance measurements (Bibring et al., 2004). Using classical methods of spectral identification (spectral parameter, Modified Gaussian Model, linear mixing), OMEGA has provided consistent identification and spatial distribution of several classes of mafic minerals (Mustard et al., 2005; Bibring et al., 2005; Poulet et al., 2007). The Noachian crust is enriched in low-Ca pyroxene, with respect to more recent lavas flows in which high-Ca pyroxene dominates, whereas high relative concentration of olivine is observed in dunes and eroded layers corresponding to ancient lava flows or melt ejectas. However, only limited petrology has yet been derived and no quantitative information on mineralogical and geochemical compositions was derived from OMEGA measurements. Previous remote sensing and in situ measurements indicate that the mafic regions are dominantly basaltic, composed mostly of feldspar and pyroxene (Bandfield et al., 2000; Hamilton et al., 2001; McSween et al., 2004, 2006a, 2006b). Two major divisions in crustal composition were recognized on the basis of their Thermal InfraRed (TIR) spectral signatures obtained by the Mars Global Surveyor / Thermal Emission Spectrometer (TES) instrument (Bandfield et al., 2000): 1) Surface Type 1, which occurs primarily in the southern highlands, and 2) Surface Type 2, which is found primarily in the northern lowlands. Recently, a reassessment of the TES data by Rogers and Christensen (2007) indicates that mineralogical diversity of the low albedo regions occurs at global and regional scales and could be classified into four groups based on relative abundances of plagioclase, pyroxene, olivine, and highsilica phase(s) (primary or secondary silicate minerals, glasses or amorphous phases with $\mathrm{Si} / \mathrm{O}$ ratios $>0.35$ ). Given the differences in spatial resolution and spectral coverage between the 
TES and OMEGA experiments, OMEGA data acquired over the mafic regions should be also quantified in terms of modal mineralogy in order to provide new insights on the martian igneous processes.

NIR spectroscopy is based on the principle that molecular overtone and combination vibrations as well as electronic crystal field transitions occur within a mineral (or rock) that are directly related to the crystal structure and composition, i.e. the mineralogy (Burns, 1993). Laboratory studies have demonstrated that the resulting absorption features in a NIR spectrum of a mineral allow to characterize the mineral. Although NIR spectroscopy has been extensively used in chemistry and physics for many decades, this technique has been applied to the qualitative and quantitative analysis of planetary surfaces only relatively recently. Deconvolving a NIR reflectance spectrum to mineral abundance in an unambiguous way is indeed difficult, because the spectra are complex nonlinear functions of several parameters such as grain size, abundance, and material opacity. Multiple scattering theories can provide approximate solutions to the radiative transfer in a compact medium. Employing such a theory in concert with optical constants of components allows computational exploration of the extensive space of parameters. A widely accepted theoretical model describing such scattering has been developed by Hapke (1981) and has been used to analyze the surface properties of the Moon, asteroids and satellites (e.g., Johnson and Grundy, 2001; Cruikshank et al., 2003, 2005; Denevi et al., 2008). Recently, other models (Douté and Schmitt, 1998; Shkuratov et al., 1999) have started to play an important role, which gives the opportunity to extend the analysis of OMEGA spectra beyond the simple recognition of mineral type, by quantifying their abundances.

Modeling of NIR laboratory spectra has been demonstrated to provide an accurate estimate of mineral abundances for basaltic mixtures of granular materials of a wide range of particle sizes (Poulet and Erard, 2004). Based on the Shkuratov radiative transfer theory, this 
modeling technique uses a selected set of optical constants for reproducing spectra of simple and complex laboratory mixtures of mafic minerals as well as powdered and bulk samples of natural basalts. In this paper, we evaluate the performance of the modeling of OMEGA maficrich spectra under a variety of conditions and attempt to provide uncertainties on the inferred modal mineralogy and grain size. An application to the Late Noachian dissected cratered terrains (DCT) in Terra Meridiani (Arvidson et al., 2003) is presented. This region provides an excellent case for the analysis of mafic surface composition because 1) it has a low albedo, and is therefore presumably relatively free of surface dust coatings, 2) analysis of previous NIR spectral data indicates that these dark regions have strong absorption features of mafic minerals throughout the OMEGA spectral range (Gendrin et al., 2006; Poulet et al., 2008), 3) although located outside the hematite unit of Meridiani Planum, this unit is sufficiently close to the MER-B landing site which provides the opportunity to better understand the atmospheric conditions of the OMEGA observations, and 4) a comparison with TES regional modal mineralogy is possible (Rogers and Christensen, 2007). A companion paper (Poulet et al., this issue) will present an analysis of the surface spectra from a dozen other selected regions in order to determine their surface mineralogy and their petrology within the limits of the current uncertainties in the modeling.

\section{Approach}

\subsection{Choice of the scattering model}

One of the significant challenges in the use of reflectance spectroscopy for quantitative analysis of planetary surface composition is to separate the physical effects (e.g., particle size) from composition. Employing scattering models to explore the extensive parameter space presents the advantage to take into account the influence of grain sizes and to include 
spectrally "neutral" components. The Shkuratov radiative transfer model is here applied for fitting the spectra (Shkuratov et al., 1999). Poulet et al. (2002) discussed its relevance and efficiency relative to other scattering models, in particular to the Hapke model and its derivatives. The model has been also tested to determine the type of mixture (intimate, spatial or bedrock), the relative proportions and the grain sizes of components of laboratory mineral samples (Poulet and Erard, 2004). Note that the model is not able to simulate thin coatings or rinds on surfaces. The tests presented in this paper validate the spectral modeling to determine the compositional and physical properties of a multi-component, granular, and mafic surface.

Given the optical constants of the end-members, the model has two free parameters for each end-member: the average grain size (we here consider one grain size per end-member) and the relative abundance. Since aerosols affect the spectral slopes, one additional free parameter is used to adjust the continuum spectral slope. The spectra are fitted in the 0.99$2.49 \mu \mathrm{m}$ wavelength range (OMEGA SWIR-C channel) using a simplex optimization algorithm: the synthetic spectrum combines, in a nonlinear way, the spectral properties of the minerals selected to be part of the admixture in proportion to their abundance. Upon obtaining a fit to the data spectrum, the algorithm supplies the user with a model-derived spectrum as well as the percentage and the grain size of each end-member used in the fit. The proportions

are reported as volume $\%$. The optimization is performed under the constraint that the sum of the fractions of various components be equal to 1 . The quality of the fit with its resultant mineralogy is quantified by the difference between the model-derived spectrum and the actual data spectrum, measured by the Root Mean Square residual (RMS).

\subsection{Choice of the end-members}

The method used assumes an a priori choice of end-members supposed to be present in the analyzed terrain. We select potential end-members by satisfying the following 
characteristics of the spectra extracted from typical mafic terrains: low albedo, shape and depth of the 1- and 2- $\mu \mathrm{m}$ absorptions, and spectral slope. If a given set does not lead to low RMS whatever the abundances and grain sizes, other minerals are included and this iterative process is performed until a satisfactory optimization is obtained. For the mafic terrains, low and high-calcium pyroxenes are included, as well as olivine. A spectrally featureless low albedo component in the NIR is also required to lower the average spectral reflectance and to reduce the spectral contrast. Oxides such as magnetite display this neutral opaque behavior. Because the observations of the Martian surface by TES have demonstrated that plagioclase is a major component of low albedo regions (e.g., Bandfield, 2002), this mineral is included as an end-member. Note that these minerals are not the same than those used in the various TES analysis. Bright dust is also added to the end-member set, although only a small amount is expected on the basis of the low overall reflectance. The library of spectral end-members is shown in Table 1.

In order to estimate the abundance of each mineral, the model needs the optical constants of all the materials involved. The real and imaginary indexes can be calculated from laboratory measurements of their transmission spectra (Roush et al. 2007 and references herein). However, such experimental methods are hard to implement and cannot be applied for some end-members such as the Martian dust since it is a complex mixture of various minerals of poorly known composition. Empirical methods exist to numerically estimate the imaginary index of the constituent of a granular sample from its reflectance spectrum (Lucey, 1998; Shkuratov et al., 1999; Poulet and Erard, 2004; Roush et al., 2007). Using the invertible property of the Shkuratov model, the mean optical properties of any material can be found if the a priori knowledge of the real index (which may be considered constant in the 1-2.5 $\mu \mathrm{m}$ range) and the effective optical path length are known (Shkuratov et al., 1999). This method, already used to derive optical constants of some mafic minerals in Poulet and Erard (2004), 
was successfully compared to other methods for materials with imaginary index values relatively low (Roush et al., 2007). Here, it is applied to laboratory reflectance spectra of mineral samples well characterized in terms of composition and grain size (Table 1). The derived imaginary index values for the dark oxides (magnetite and ilmenite) are ranged between 0.001 and 0.01 , which is much smaller than the measurements obtained from independent measurements (Huffman, 1977). Using the Huffman's values would lower the abundances of the opaque oxide minerals, which are expected to be of the order of a few percents at most, but it should not affect the abundances of other materials.

The composition of the dust is not well known, so that we decided to include it in our modeling as an empirical end-member, whom the optical constants are calculated from OMEGA observations. The reflectance spectrum we use for the Martian dust is an average over several OMEGA pixels of several orbits that cover uniform bright regions located in the northern hemisphere of Mars. The calculation of imaginary index for the dust component was done assuming an effective optical path of $5 \mu \mathrm{m}$. This value is larger than the upper limit of the grain size distribution of aeolian surface sediments on Mars, as inferred from Viking Lander data and Pathfinder (Tomasko et al., 1999). However, considering a lower value is excluded because it will break the principle of the geometrical optics of the model.

A comparison of the spectral signatures of the end-members is shown in Fig. 1A. The spectra are computational results. The calculation of the plagioclase spectrum incorporates inclusions of magnetite using effective medium theory (see section 2.3). The grain size of a mineral modifies the absorption band depth (Fig. 1) and thus the detection limit and the relative abundance of the material in the mixture. The existence of an optimal particle size for each absorption feature for a specific mineral of a given texture that maximizes its band depth has been observed by many workers (e.g., Clark and Lucey, 1984; Hapke, 1993). For mafic material, the optimal particle size ranges between a few tens and a few hundreds of 
micrometers (Harloff and Arnold, 2001). The sensitivity to the grain size will be estimated (see section 3.2).

We note that our spectral library contains a rather small number of end-members in comparison to other quantitative methods, especially linear deconvolution (e.g., Hamilton et al., 2001; Combe et al., 2008). However, the major spectral types of material responsible for the shape and intensity of the NIR spectra of basalts and their derived products are represented:

1) A first type of materials exhibiting marked absorption bands (pyroxenes, olivines). The 1and $2-\mu \mathrm{m}$ absorption bands of the pyroxenes result from crystal field transitions of iron in octahedral coordination. The positions of these absorptions vary systematically as a function of composition and crystal structure (Adams, 1974; Cloutis and Gaffey, 1991; Schade et al. 2004). The presence of calcium, iron, and magnesium in the crystallographic sites affects the locations and shape of these distinct absorptions. The small number of pyroxene end-members used in our study may be not representative of the Martian crust. In the presence of mixtures of pyroxene of intermediate compositions, it could be very difficult to reliably isolate the endmember components. However, analyses of OMEGA spectra using the Modified Gaussian Model (MGM) developed by Sunshine et al. (1990) shows that all average band positions and uncertainties for OMEGA spectra plotted within the range of the two major single phase pyroxenes, namely Low-Calcium Pyroxene (LCP) and High-Calcium Pyroxene (HCP) (Kanner et al., 2007). For this study, we are thus interested in calcium and iron substitutions, which are known to have the most significant effects on the NIR band position by systematically shifting the 1 - and $2-\mu \mathrm{m}$ features to longer wavelengths with increasing abundance (Cloutis and Gaffey, 1991).

2) A second type corresponding to almost neutral (NIR spectrally featureless) minerals, such as plagioclases; the presence of such minerals plays a strong role by controlling the overall 
albedo and by reducing the spectral contrasts due to absorption bands of mafic minerals (see section 3.1). However, within this type, our analysis cannot discriminate between plagioclase and other potential candidates such as some high-silica anhydrous phases. Some TES analyses revealed that high-silica phase(s) could be one of the significant mineral groups for many low albedo regions. Primary high-silica volcanic glasses are potentially indistinguishable from some secondary amorphous or poorly crystalline high-silica materials in the thermal infrared spectral region (Bandfield, 2002; Wyatt and McSween, 2002; Kraft et al., 2003; Michalski et al., 2003; Morris et al., 2003; Ruff, 2004; Koeppen and Hamilton, 2005), which complicates the interpretation of high-silica phase(s) detected by the TES instrument. OMEGA detects hydrated minerals including phyllosilicates in some specific geological units that are disconnected from the low albedo mafic-rich regions (Poulet et al., 2005). Given the strong and unambiguous signatures of the phyllosilicates in the NIR, we can therefore exclude them from the spectral library with confidence. Actually, it is possible that the phyllosilicate abundances in the TES data could be misrepresented if phyllosilicates on the Martian surface have a spectral contrast much lower or higher than the average solid phyllosilicates in the Arizona State University library (Rogers and Christensen, 2007). High spatial and spectral resolution reflectance data acquired by the Mars Reconnaissance Orbiter Compact Reconnaissance Imaging Spectrometer for Mars reveal the presence of $\mathrm{H}_{2} \mathrm{O}$ - and $\mathrm{SiOH}-$ bearing phases on the Martian surface, but they are found in very localized areas, typically in finely-stratified deposits exposed on the floor of and on the plains surrounding the Valles Marineris canyon system (Milliken et al., 2008). The other high-silica phases are spectrally featureless in the NIR, so that they could be also present and /or replace the role of the plagioclase component. However, we choose not to include high-silica end-members in our spectral library, because the nature and the abundance of high-silica phases (from $\sim 10$ to $30 \%$ depending on the analyses, e.g., McSween et al., 2003) are still controversial and because the 
significant abundance is mainly found in the TES type II surface of the northern hemisphere that will not be considered in our further studies.

3) A third one made of strongly absorbing minerals, such as iron oxides. In terrestrial basaltic materials, they are in general embedded in the plagioclase matrix, and their presence results in a decrease in both band depth and overall reflectance (Harloff and Arnold, 2001). These minerals (magnetite, ilmenite) are primarily associated with basaltic soils and rocks on Mars (e.g., Morris et al., 2006).

Further examples presented in the next sections will demonstrate that the endmembers listed in Table 1 can satisfactorily reproduce the spectra of the low albedo regions.

\subsection{Choice of the end-type of surface}

Assuming a homogeneous unconsolidated surface, many low albedo regions have a thermal inertia consistent with sand-sized particles (Palluconi and Kieffer, 1981; Edgett and Christensen, 1991; Rogers and Christensen, 2003). One specific mixture can be therefore considered: intimate or "salt-and-pepper" mixture in which the single scattering albedo in the scattering models is calculated for each component grain and then averaged (Poulet et al., 2002). However, numerical and laboratory experiments show that an intimate mixture of the different pure components usually present in basalt (plagioclase, pyroxenes, olivine, oxide) failed to reproduce the spectral characteristics of a basaltic sample (Poulet and Erard, 2004 and references therein). This problem is related to the fact that the dominant minerals present in basalts are bright in the NIR. The color and darkness of basaltic rocks are strongly controlled by the proportion of iron oxides, especially magnetite (e.g., Faye and Miller, 1973). A successful modeling of basalt was derived using another kind of mixture (intramixture) to consider: "dark basalt" where plagioclase grains are associated with inclusions of dark iron oxides (Poulet and Erard, 2004). When mixed with the other major minerals present in basalt, 
these types of plagioclase grains, whose scattering properties are calculated by effective medium theories (Bohren and Huffman, 1983) can simulate the reflectance spectra of basalts (Poulet and Erard, 2004).

\section{Estimate of the abundance uncertainty}

\subsection{Sensitivity to the end-member}

The formal error in mineral abundance derived using NIR spectroscopic measurements under optimum laboratory conditions has been estimated to be 5-10\% (Poulet and Erard, 2004). This uncertainty is different for each mineral depending on the strength, width, and position of the spectral features, as well as the spectral properties of the other minerals present. Olivines and pyroxenes have strong absorption bands in the wavelength range under consideration and their abundances are well derived $(<10 \%)$, especially for grain size larger than several tens of $\mu \mathrm{m}$. Plagioclase is spectrally flat in NIR, making it difficult to estimate relative abundance with an uncertainty better than $10 \%$. These uncertainties likely increase on Mars owing to the lower signal to noise ratio of OMEGA compared to laboratory instruments and the contribution of the atmospheric components. However, the presence of dark plagioclase plays a strong role by controlling the overall albedo and by reducing the spectral contrasts due to marked electronic absorption bands of mafic minerals (Fig. 2). The shape and the band depths of the OMEGA spectra of mafic-rich terrains are not consistent with those of spectra of pure mafic minerals (Fig. 2A), demonstrating that other non-mafic components such as plagioclase are likely present. As mentioned previously, the TES spectra of the low albedo terrains exhibit the signatures of plagioclase, which reinforces our confidence to include this mineral as an end-member capable to adjust the shallow mafic bands. Of special interest is the effect of pyroxene when mixed with olivine (Fig. 2D). The presence of 
pyroxene can be detected thanks to the $2 \mu \mathrm{m}$ band, which is important for petrological consideration.

Both HCP and LCP are identified in the surface composition of the low albedo terrains (Bibring et al., 2005). The presence of LCP was not supported by the original TES analyses because this mineral was modeled at best at the traditional TES detection limits (10-15\%) (Christensen et al., 2000). A test of the presence of this mineral and the inferred abundance is studied from one spectrum extracted from the DCT unit. The model fit is highly degraded (Fig. 3) when low-calcium pyroxene is removed as a component, demonstrating the high sensitivity of the model to this mineral ${ }^{1}$.

One of the applications of this work is to determine the elemental composition from modal mineralogy (companion paper). The mineral chemistry of the end-members is therefore essential for determining the petrogenesis of the pyroxene-bearing rocks. Moreover, most of SNC (Shergottites, Nakhlites, and Chassignites) meteorites, which are assumed to have originated from Mars (e.g., Treiman, 1995), exhibit diverse mineralogy including the two major single phase pyroxenes HCP and LCP. The major LCP phase detected in the SNCs is pigeonite (a part of the spectral library); their HCP phase is more often augite rather than diopside used in the previous modeling of the DCT spectrum. Here we investigate the ability to refine pyroxene composition by taking augite as the HCP end-member (Table 1). Firstorder examination of the spectral properties of augite with the same particle size than diopside reveals two main absorption bands similar to those of the diopside (Fig. 1). However, two small differences exist: 1) the band positions of augite are slightly shifted to shorter wavelengths by a few tens of nm, which is consistent with the lower Ca content in augite, 2) the band depths are more pronounced for augite (with a $2-\mu \mathrm{m}$ band depth equal to $14 \%$ in

\footnotetext{
${ }^{1}$ Small noticeable misfits between measured and best-fit spectra are observed at the shortest and longest wavelengths of the OMEGA data. Their causes are not well understood but may result from an instrumental effect (small time-dependent deviations from linearity that depends on the flux received by the instrument), atmospheric effects, and/or precise end-member selection. But these discrepancies are still inside the instrumental error bars of $2 \%$.
} 
comparison to $9 \%$ for diopside), which translates to a larger absorption coefficient. When augite is used as an HCP end-member, a smaller value of the HCP abundance is then found in the modeling of the DCT terrain (Fig. 3, Table 2). However, we observe that the discrepancies are within the uncertainties and the ratio $\mathrm{LCP} /(\mathrm{HCP}+\mathrm{HCP})$ is roughly the same. To better evaluate the numerical uncertainty associated with the choice of the HCP end-member, the same sensitivity test is extended to several thousand spectra extracted from the DCT unit. Both HCP end-members provide acceptable solutions with similar low values of RMS. The effect of replacing diopside by augite on the modal mineralogy is shown on Fig. 4. The abundance of HCP decreases by $\sim 2.5 \%$ when using augite, while the abundances of all other end-members remain the same. The ratio $\mathrm{LCP} /(\mathrm{HCP}+\mathrm{LCP})$ varies slightly: $0.29+/-0.05$ for augite in comparison to $0.25+/-0.07$ for diopside. This difference is within the uncertainties of the model. Consequently, although the HCP phase cannot be uniquely derived from the remote measurements of OMEGA, the modal composition using major end-members of different phases (LCP, HCP, plagioclase and dust) can be assessed.

\subsection{Sensitivity to the grain size}

In the tests done on laboratory basaltic samples, the inferred grain sizes are accurate within a factor of 2, which was considered to be enough to discriminate between large categories of grains $(10 \mathrm{~s}, 100 \mathrm{~s}, 1000 \mathrm{~s} \mu \mathrm{m})$ and therefore between formation processes (Poulet and Erard, 2004). However, grain size is an important parameter that controls the shape and the depth of any absorption as mentioned previously and it therefore merits a special attention. The primary and spectrally neutral mineral plagioclase is actually expected to be more sensitive to this parameter than any other mineral, because increasing the grain size (i.e. absorption) could be compensated by a decrease of the abundance of plagioclase, raising the question about the uniqueness of the final solution. The effect of grain size can be illustrated 
using models in which all end-members have identical grain size, the optimization being made on this size with their relative abundance as a free parameter (Fig. 5). First, it is important to note that the model fails to reproduce the pyroxene bands if all the grain sizes are forced to be smaller than $50 \mu \mathrm{m}$ or larger than $200 \mu \mathrm{m}$. This shows that the best fit of the grain size of the pyroxene phases is in the $50-200 \mu \mathrm{m}$ range. Second, variations of $5-10 \%$ are seen in the plagioclase abundance when the grain sizes vary from 100 to $200 \mu \mathrm{m}$. The abundances of the pyroxenes are also affected within $5 \%$ of the best fit value, although the RMS values smaller than $0.30 \%$ are still acceptable.

The purpose of the next set of numerical experiments is to further examine the effect of the grain size of plagioclase on the final solution and to determine the uncertainties on the inferred abundance of minerals. Fig. 6 shows the result of the fitting procedure of the DCT spectrum: the grain size of plagioclase is forced to be $10,100,500$ and $1000 \mu \mathrm{m}$ while keeping free all the other parameters. We remind that magnetite inclusions are embedded in the plagioclase, but the content of this oxide mineral is the same for each calculation. The model fails to reproduce the data spectrum if the grain sizes are too large (500 and $1000 \mu \mathrm{m}$, cyan and green spectra respectively), because such large grain sizes reduce too strongly the pyroxene bands. When the grain size is set at smaller values than the best fit value of $150 \mu \mathrm{m}$ (blue spectrum), the model-derived spectra (red and orange spectra) are satisfactory, but the RMS is significantly larger by about $30 \%$ than the RMS obtained for the best fit. Despite the NIR spectrally featureless character of plagioclase, these simulations show that its grain size, and thus its abundance, are constrained, with grain size within a range of a few tens to a few hundreds of micrometers and abundance within 40-60\% range.

\subsection{Sensitivity to the initial conditions}


Due to the nonlinear formulation of the Shkuratov theory, the inversion problem has to be solved using an iterative approach. A downhill simplex technique is used here to find the RMS residual between measured spectrum and computed spectrum (Press et al., 2002). This optimization procedure depends on the initial conditions. We design another sensitivity test to discuss the effect of the input parameters on the validity of the inferred modal mineralogy. We vary the starting grain size and abundance parameters for each end-member and assess the consistency of resultant grain size and abundance solutions. The test is done on a large number of spectra extracted from the DCT unit of Terra Meridiani in order to better evaluate the uncertainties. Comparison between the the two simulations shows that the final average values of the abundances vary only slightly with the values of the starting parameters (Fig. 7): $28+/-3 \%$ versus $28+/-5 \%$ for HCP, $10+/-4 \%$ versus $12+/-3 \%$ for LCP and $52+/-4 \%$ versus $47+/-7 \%$ for plagioclase. Of special interest is the increase of pyroxene abundances versus the pyroxene band depth value. This expected compositional trend makes us confident on the methodology and the values of the abundances. The plagioclase abundance is less robust but the distributions and the averaged values of abundances are still consistent within the uncertainties of the method $(\sim 10 \%)$. By contrast, the initial conditions significantly affect the grain size parameter. As the input grain size parameter decreases or increases, the resultant solutions similarly shifted to the same part of the parameter space. For instance, the final grain sizes of HCP are close to the initial value of $100 \mu \mathrm{m}$ for simulation 1, while the grain sizes of the simulation 2 that started with a $300 \mu \mathrm{m}$ value, are ranged between 200 and $500 \mu \mathrm{m}$. This reveals that the starting parameters do have a significant effect on the resultant solutions whatever the mineral. However, the ranges of the final acceptable solutions can be evaluated. Most of the final values of the plagioclase grain size clearly plot in the $50-150 \mu \mathrm{m}$ range for the two simulations. The same trend is observed for the LCP component. The HCP grain size 
shows large standard deviation, but still in the range of a few $10 \mathrm{~s}$ to a few $100 \mathrm{~s}$ of micrometers as discussed previously.

The simplex algorithm calculates thousands of possible mixtures before reaching a final solution. In order to illustrate the range of values considered in the fitting effort and provide an estimate of the uncertainty in the final results, we plot the RMS versus component abundances and diameters for several representative pyroxene band depths $(0.01,0.02,0.03$, 0.04, 0.05 and 0.06) in Fig. 8. Apart from the grain size of the Martian dust component that is initially fixed, the grain sizes are ranged in the $10 \mathrm{~s}$ to a few $100 \mathrm{~s} \mu \mathrm{m}$, which confirms the previous estimates. The parameter space of the abundances is $40-55 \%$ for plagioclase, $25-$ $35 \%$ for HCP, $10-15 \%$ for LCP, $5-10 \%$ for the dust, and less than $5-10 \%$ for olivine. These

variations are also in good agreement with the uncertainties previously determined. For a given spectrum and for values of RMS lower than $0.35 \%$, the excursions of the parameter are even smaller.

\subsection{Sensitivity to the olivine mineral}

Olivine has strong absorption bands in the wavelength range under consideration, and its abundance should be well constrained. However, the band strongly depends on the grain size as well as the $\mathrm{Mg} / \mathrm{Fe}$ ratio: the larger the grains, and/or the smaller the Fo content, the higher the detection (Fig. 1C, Fig. 1D). An important outcome is that we may not accurately identify olivine in mixtures such as the pyroxene-rich regions that could contain as much as $15-20 \%$ forsterite, if the olivine grain size is in the micrometer range (Poulet et al., 2007). The modeling shown in Fig. 9 confirms that an addition of $10-15 \%$ of olivine of grain size equal to $10 \mu \mathrm{m}$ does not affect the modeled-derived spectrum, so that we cannot exclude its presence. This uncertainty represents the "worst case" for the olivine detection; increasing the grain size and/or decreasing the Fo number strongly enhances the olivine band, favorizing thus the 
identification of the olivine by OMEGA. Consequently, this decreases the uncertainty on the abundance of this mineral. For instance, it has been demonstrated that only $5 \%$ of Fo 10 olivine can be detected by OMEGA if the grain size is $100 \mu \mathrm{m}$ (Poulet et al., 2007). Since the olivine abundance is function of the grain size and iron content, we consider Fo 90 olivine with grain size fixed at $100 \mu \mathrm{m}$ in the further applications of our model.

\subsection{Sensitivity to the aerosols}

The highly variable optical thickness of aerosols in the Martian atmosphere has a significant impact on the observed reflectance factor in the NIR wavelength range. A model has been developed to analyze and remove the contribution of Martian aerosols in OMEGA observations (Vincendon et al., 2007a). This model is based on a Monte-Carlo radiative transfer code that includes multiple scattering, coupled with optical properties of aerosols constrained from previous studies (Ockert-Bell et al., 1997; Tomasko et al., 1999) and specific Emission Phase Function (EPF) OMEGA observations (Vincendon et al., 2007b). A validity test of the aerosol removal method was performed in January 2006 thanks to an EPF observation of Terra Meridiani by OMEGA, while Panoramic Camera (Pancam) aboard Opportunity was measuring the aerosol optical depth from the ground (Lemmon et al., 2004; 2006; Vincendon et al., 2007b). Briefly stated, the model depends on two parameters: the wavelength dependent albedo of the surface and the optical depth of aerosols at one wavelength. If the aerosol optical depth is known, the model can retrieve the reflectance spectra of the surface free of aerosol contribution. This method can be therefore applied to the OMEGA data cubes over Terra Meridiani because of the proximity of the MER-B that measures the aerosol optical depth thanks to Pancam observations. A test was done in using two overlapping observations of Terra Meridiani obtained with different amounts of dust in the atmosphere (Fig. 10). After removing the aerosol contribution, the derived surface spectra 
of the same region are similar, making us confident in the accuracy of our aerosol correction method. Aerosols are characterized by a decreasing continuum slope between $1 \mu \mathrm{m}$ and 2.5 $\mu \mathrm{m}$. The removal of their contribution increases the spectral signatures and modifies the general slope of the spectra (Fig. 11).

We now aim to estimate the uncertainties on the modal mineralogy resulting from the aerosols contribution. For this investigation, we model several thousands of aerosol-cleaned OMEGA spectra, whom the inferred mineralogy was previously derived from uncorrected spectra (see simulation 1 of Fig. 7). Small differences between the abundances and the grain size distributions exist, but they are all within the derived uncertainty of the method (Fig. 12): $29+/-4 \%$ in comparison to $28+/-3 \%$ for the HCP component, $11+/-4 \%$ versus $10+/-4 \%$ for LCP and $50+/-6 \%$ versus $52+/-4 \%$ for plagioclase This sensitivity test indicates that the application of our spectral model to OMEGA spectra uncorrected for the aerosol contribution produces reliable values.

\section{Application of the method to the DCT unit of Terra Meridiani}

\subsection{Derived mineralogy}

We use the spectral model on OMEGA reflectance spectra extracted from a part of the mafic-rich regions observed in Terra Meridiani, also referred as DCT unit (Arvidson et al., 2003). Detailed mapping of the Terra Meridiani region shows that different geological units are actually stratigraphically present. Hematite-bearing plains ( $\mathrm{Ph}$ unit) are at the top of a section of layered material (referred as etched terrains E unit) that is hundreds of meters thick and extends beneath the Opportunity landing site; these etched terrain materials sit unconformably on the late Noachian dissected cratered terrain materials (Hynek et al., 2002; Arvidson et al., 2003; Edgett, 2005). OMEGA data covering the etched terrains show enhanced water bands at 1.9 and $3.0 \mu \mathrm{m}$ (Jouglet et al., 2007; Poulet et al., 2008) and, in some 
localities, evidence for the presence of monohydrated and polyhydrated sulfate minerals where discrete stratigraphic horizons are exposed (Arvidson et al., 2005; Griffes et al., 2007).

Orbital reflectance spectra obtained by OMEGA over the landing site are well reproduced by pyroxene, plagioclase feldspar, crystalline hematite (i.e., concretions), and nano-phase iron oxide dust signatures, consistent with Pancam and Mini-TES observations (Arvidson et al., 2006). Of special interest for our study are the detected signatures of pyroxenes associated with the DCT unit (Fig. 13). We thus focus our analysis on the northern part of this unit where significant LCP signatures were identified (Gendrin et al., 2006). Using all the spectral endmembers of the skeleton library listed in Table 1, the model is applied to each OMEGA pyroxene-rich spectrum of the studied region outlined in Fig. 13. All the parameters are free except for the olivine and the dust grain sizes fixed at $100 \mu \mathrm{m}$ and $5 \mu \mathrm{m}$ respectively as justified previously. Two different simulations starting with different input parameters were done and the final modal mineralogy with the best RMS is eventually retained for each analyzed spectrum. Derived modal mineralogy is given in Table 3 along with the results of TES for the same region (Rogers and Christensen, 2007). The uncertainty on any mineral abundance is calculated as the standard error of the data sample that consists of $\sim 3000$ spectra (Fig. 14). As expected, plagioclase and pyroxene are the dominant group of minerals. The only additional mineral group modeled at the detection limit of $5-10 \%$ is the Martian dust. The presence of this component is supported by the presence of significant ferric absorption bands in the visible wavelength range best attributed to the ferric dust (Poulet et al., 2008).

The DCT unit falls within the globally defined low albedo, intermediate to high thermal inertia regions with exposed sands (Arvidson et al., 2003). The inferred grain sizes in the medium to fine sand size range is consistent with the thermal inertia (200 to $400 \mathrm{~J} \mathrm{~m}^{-2} \mathrm{~K}^{-1}$ $\mathrm{s}^{-1 / 2}$ ) and albedo values derived for these dark regions typically composed of coarse-grained (100-500 $\mu \mathrm{m})$ particles (Palluconi and Kieffer, 1981; Edgett and Christensen, 1991). 


\subsection{Comparison with previous spectroscopic studies}

Results from this work confirm those of previous studies (Bandfield et al., 2000; Christensen et al., 2000; Bandfield, 2002; McSween et al., 2003) that the low albedo regions such as DCT unit in Terra Meridiani are dominated by plagioclase and mafic minerals. More specifically, the TES deconvolution of spectra extracted from the DCT region provides plagioclase, HCP, and high-silica phases as the dominant mineral groups (Rogers and Christensen, 2007). In the TES analysis, additional mineral groups including carbonate, sulfate, orthopyroxene and quartz are also modeled below the TES detection for a total of $19 \%$. As noted in section 2.2, high-silica phases (and quartz) are spectrally neutral in the NIR. The plagioclase abundance inferred by OMEGA can be then compared to a mineral group referred as neutral components, for which the abundance is the combined TES abundances of plagioclase, high silica phases and quartz (Table 3). The mineral abundances for the HCP and neutral components are in a proportion similar to the TES-Type I spectra found in the low albedo terrains (Wyatt and McSween, 2002; McSween et al., 2003), as well as with the regional studies of Rogers and Christensen (2007) within the uncertainties of the models. Not surprisingly, this work gives a plagioclase/pyroxene ratio of $1.25+/-0.20$, which is also consistent with the values of previous works (Bandfield, 2002; Rogers and Christensen, 2007).

The most significant deviation between the TES and OMEGA analyses is in the abundance of LCP unambiguously detected in the OMEGA data. In other low albedo regions, LCPs (orthopyroxene, pigeonite) are modeled at, or above, the TES detection limits (Rogers and Christensen, 2007). Updated analyses report that a low-calcium component is definitively required to reproduce the TES spectral properties of the low albedo regions (Hamilton and Koeppen, 2007). 
The calculated $\mathrm{LCP} /(\mathrm{HCP}+\mathrm{LCP})$ ratio (Table 3) significantly differs from modal abundances of the ancient Noachian terrains estimated from a normalized MGM band strength ratio $(\mathrm{LCP} /(\mathrm{LCP}+\mathrm{HCP}))$ of OMEGA spectra (Kanner et al., 2007). A direct comparison cannot be investigated because Terra Meridiani was not considered in their paper. However, the lowest relative abundance of LCP derived by their MGM analyses is $39+/-10$, which is still larger than our inferred value of $26+/-8$. Further specific application of the MGM to the study of the DCT unit should be done so as to improve the comparison between our modeling procedure and the MGM tool.

Another discrepancy is the TES abundance of olivine at, or above, the limit of detection. Although OMEGA detected olivine (Mg-rich compositions) in extensive regions of the pyroxene-rich zones (Poulet et al., 2007), we restate that the abundance of this mineral is not well constrained if the grain size is smaller than a few tens of micrometers (section 3.4). Therefore, we cannot rule out the presence of this very fine grain-sized olivine in the proportion of $\sim 10-15 \%$. The inconsistency between OMEGA and other experiments regarding the possible presence of olivine in small abundance was already reported in the combined OMEGA/Opportunity observations of Meridiani Planum (Arvidson et al., 2006). Different factors that could influence the modeled abundance of olivine by OMEGA were proposed: 1) olivine and pyroxene mixtures produce reflectance spectra that are non-linear mixtures with a bias toward spectral features of pyroxene due to the fact that pyroxenes are more opaque than olivines (Singer, 1981), 2) the addition of dust can further obscure olivine features in reflectance spectra, 3) preferential surface weathering of olivine grains could occur, in comparison to other minerals.

The composition of the DCT surface materials, assuming that the observed mineral assemblage represents a single igneous lithology, corresponds to a mafic rock. A more precise 
classification using a comparison between the composition of other Martian low albedo regions and SNCs is dedicated to the companion paper.

\section{Conclusion}

This paper presents the results of a spectral modeling, used to extract modal mineralogy of the Martian low albedo regions from OMEGA spectra. Complementary to the previous study of Poulet and Erard (2004), which showed that this model satisfactorily derived the abundances and grain sizes of minerals of laboratory basaltic samples from their NIR spectra, the sensitivity tests developed in this present analysis indicate that the model can retrieve a reasonable estimate of the surface mineralogy of the low albedo regions from OMEGA data. The model successfully reproduces the spectra using a set of restricted endmembers. Lack of the correct end-members in the library and/or grain sizes results in a poor model fit, which supports the uniqueness of the solution by demonstrating that good fit cannot be obtained by a fortuitous combination of incorrect end-members. However, our results show that more subtle outcomes, such as the precise identification of HCP (augite versus diopside) cannot be derived uniquely from the OMEGA spectra. Similarly, the presence of almost NIR neutral components is identified and their abundance quantified, although their specific characterization (e.g, plagioclase) cannot be assessed unambiguously: they could as well be constituted of primary volcanic glass, amorphous silica coatings, and/or poorly crystalline material in weathering rinds.

The modal mineralogy is robust to the initial values of parameters required for the optimization step. Despite the significant effect of the aerosols on the overall shape of OMEGA spectra, the model can be confidently used on the spectra uncorrected for the aerosols. Inferred modal compositions are accurate to $+/-5-15 \%$ for the major minerals 
(pyroxenes and plagioclase). The detection limit of olivine depends on the grain size and increases to $\sim 15 \%$ for Mg-rich olivine of very fine grains (10 $\mu \mathrm{m}$ in size typically).

A surface of only plagioclase, pyroxenes (both HCP and LCP) and Martian dust can account for the overall spectral properties of the late Noachian dissected cratered unit in Terra Meridiani given the instrument noise and uncertainties in the current modeling. The companion paper discusses the mineralogy associated with a dozen low albedo regions inferred from the model presented in this work and addresses petrologic implications. 


\section{References}

Adams, J.B., 1974. Visible and near-infrared diffuse reflectance: Spectra of pyroxenes as applied to remote sensing of solid objects in the Solar System. J. Geophys. Res. 79, 48294836.

Arvidson, R.E., Seelos, F.P., Deal, K.S., Koeppen, W.C., Snider, N.O., Kieniewicz, J.M., Hynek, B.M., Mellon, M.T., Garvin, J.B. 2003. Mantled and exhumed terrains in Terra Meridiani, Mars. J. Geophys. Res. 108, doi:10.1029/2002JE001982.

Arvidson, R.E., Poulet, F., Bibring, J.-P., Wolff, M., Gendrin, A., Morris, R.V., Freeman, J.J., Langevin, Y., Mangold, N., Bellucci, G., 2005. Spectral reflectance and morphologic correlations in eastern Terra Meridiani, Mars. Science 307, 1591-1594.

Arvidson R.E., and 24 colleagues, 2006. Nature and origin of the hematite-bearing plains of Terra Meridiani based on analyses of orbital and Mars Exploration rover data sets. J. Geophys. Res. 111, doi:10.1029/2006JE002728.

Bandfield, J.L., 2002. Global mineral distributions on Mars. J. Geophys. Res. 107(E6), doi:10.1029/2001JE001510.

Bandfield, J.L., Hamilton, V.E., Christensen, P.R., 2000. A global view of Martian surface compositions from MGS-TES. Science 287, 1626-1630.

Bibring, J.-P., and 13 colleagues, 2004. OMEGA: Observatoire pour le Minéralogie, l'Eau, les Glaces et l'Activité. ESA Spec. Publ. 1240, 37-49. 
Bibring, J.-P., Langevin, Y., Gendrin, A., Gondet, B., Poulet, F., Berthe, M., Soufflot, A., Arvidson, R.E., Mangold, N., Mustard, J.F., Drossart, P., Omega Team, 2005. Mars surface diversity as revealed by the OMEGA/MarsExpress observations. Science 307, 1576-1581.

Burns, R.G., 1993. Origin of Electronic Spectra of Minerals in the Visible-Near Infrared Region. In Remote Geochemical Analysis: Elemental and Mineralogical Composition, ed. C.M. Pieters and P.A.J. Englert, pp. 3-29. Cambridge: Cambridge Univ. Press.

Bohren, C.F., Huffman, D.R., 1983. Absorption and Scattering of Light by Small Particles. Wiley, New York.

Christensen, P.R., Bandfield, J.L., Smith, M.D., Hamilton, V.E., Clark, R.N., 2000. Identification of a basaltic component on the martian surface from Thermal Emission Spectrometer data. J. Geophys. Res. 105 (E4), 9609-9621.

Clark, R.N., Lucey, P.G., 1984. Spectral properties of ice-particulate mixtures and implications for remote sensing. I - Intimate mixtures. J. Geophys. Res. 89, 6341-6348.

Cloutis, E.A., Gaffey, M.J., 1991. Pyroxene spectroscopy revisited: Spectral compositional correlations and relationship to geothermometry. J. Geophys. Res. 96, 22809-22826.

Combe, J.-P., and 10 colleagues 2008. Analysis of OMEGA / Mars Express data hyperspectral data using a Multiple-Endmember Linear Spectral Unmixing Model (MELSUM): Methodology and first results. Planetary Spa. Sci., in press. 
Cruikshank, D.P., Roush, T.L., Poulet, F., 2003. Quantitative modeling of the spectral reflectance of Kuiper Belt objects and Centaurs. C. R. Physique 4(7), 783-789.

Cruikshank, D.P., Owen, T.C., Ore, C.D.; Geballe, T.R., Roush, T.L., de Bergh, C., Sandford, S.A., Poulet, F., Benedix, G.K., Emery, J.P., 2005. A spectroscopic study of the surfaces of Saturn's large satellites: H2O ice, tholins, and minor constituents. Icarus 175(1), 268-283.

Denevi, B.W., Lucey, P.G., Sherman, S.B., 2008. Radiative transfer modeling of near-infrared spectra of lunar mare soils: Theory and measurement. J. Geophys. Res. 113(E2), doi:10.1029/2007JE002929.

Douté, S., Schmitt, B., 1998. A multilayer bidirectional reflectance model for the analysis of planetary surface hyperspectral images at visible and nearinfrared wavelengths. J. Geophys. Res. 103, 31367-31390.

Edgett, K.S., Christensen, P.R., 1991. The particle size of Martian aeolian dunes. J. Geophys. Res. 96, 22,765-22,776.

Edgett, K., 2005. The sedimentary rocks of Sinus Meridiani: Five key observations from data acquired by the Mars Global Surveyor and Mars Odyssey orbiters. Mars J. 1, 5-58, doi:10.1555/mars.2005.0002.

Faye, G.H., Miller, R.M. 1973. "Blue Dragon" Basalt from Craters of the Moon National Monument, Idaho: Origin of Color, Ameri. Mineralogist 58, 1048-1051. 
Gendrin, A., and 10 colleagues, 2006. Strong pyroxene absorption bands on Mars identified by OMEGA: Geological counterpart. Lunar Planet. Sci. XXXVII. Abstract 1858.

Griffes, J.L., Arvidson, R.E., Poulet, F., Gendrin, A., 2007. Geologic and Spectral Mapping of Etched Terrain Deposits in Northern Meridiani Planum. J. Geophys. Res. 112, E08S09, doi:10.1029/2006JE002811.

Hamilton, V.E., Wyatt, M.B., McSween, H.Y., Christensen, P.R., 2001. Analysis of terrestrial and Martian volcanic compositions using thermal emission spectroscopy: 2. Application to Martian surface spectra from MGS TES. J. Geophys. Res. 106, 14,733-14,746.

Hamilton, V.E., Koeppen W.C., 2007. Global Mineral Maps of Mars: Examination of Compositional Variation Within Solid Solution Series. American Geophysical Union, Fall Meeting 2007, abstract \#P13D-1549.

Hapke, B., 1981. Bidirectional reflectance spectroscopy. 1. Theory. J. Geophys. Res. 86, 3039-3054.

Hapke, B. 1993. Theory of Reflectance and Emittance Spectroscopy. Cambridge Univ. Press, Cambridge, UK.

Harloff, J., Arnold, G., 2001. Near-infrared reflectance spectroscopy of bulk analog materials for planetary crust. Planet. Space Sci., 49, 191-211. 
Huffman, D.R., 1977. Interstellar grains. The interaction of light with a small-particle system. Adv. Phys., 26, 130-230.

Hynek, B.M., Arvidson, R.E., Phillips, R.J., 2002. Geologic setting and origin of Terra Meridiani hematite deposit on Mars. J. Geophys. Res. 107, doi:10.1029/2002JE001891.

Jouglet, D., Poulet, F., Milliken, R.E., Mustard, J.F., Bibring, J.-P., Langevin, Y., Gondet, B., OMEGA Team, 2007. Hydration state of the Martian surface as seen by Mars Express OMEGA. I - Analysis of $3 \mu \mathrm{m}$ hydration feature. J. Geophys. Res 112, Issue E8, doi:10.1029/2006JE002846.

Kanner, L.C., Mustard, J.F., Gendrin, A., 2007. Assessing the limits of the Modified Gaussian Model for remote spectroscopic studies of pyroxenes on Mars. Icarus 187, 442-456.

Koeppen, W.C., Hamilton, V.E., 2005. Discrimination of glass and phyllosilicate minerals in thermal infrared data. J. Geophys. Res. 110, E08006, doi:10.1029/2005JE002474.

Kraft, M.D., Michalski, J.R., Sharp, T.G., 2003. Effects of pure silica coatings on thermal emission spectra of basaltic rocks: Considerations for Martian surface mineralogy. Geophys. Res. Lett. 30(24), 2288, doi:10.1029/2003GL018848.

Johnson, J.R., Grundy, W.M., 2001. Visible/near-infrared spectra and two-layer modeling of palagonite-coated basalts. Geophys. Res. Lett. 28(10), 2101-2104. 
Lemmon, M. T., et al., 2004. Atmospheric imaging results from the Mars Exploration Rovers: Spirit and Opportunity. Science 306, 1753-1756.

Lemmon, M. T., and the Athena Science Team, 2006. Mars Exploration Rover atmospheric imaging: dust storms, dust devils, dust everywhere. LPSC XXXVII, LPI, Houston, TX.

Lucey, P.G., 1998. Model near-infrared optical constants of olivine and pyroxene as a function of iron content. J. Geophys. Res. 103(E1), 1703-1713.

McSween, H.Y., Jr., Grove, T.L., Wyatt, M.B., 2003. Constraints on the composition and petrogenesis of the Martian crust. J. Geophys. Res. 108(E12), 5135, doi:10.1029/2003JE002175.

McSween, H.Y., Jr., and 34 colleagues, 2004. Basaltic rocks analyzed by the Spirit rover in Gusev Crater. Science 305, 842- 845 .

McSween, H.Y., Jr., and 41 colleagues, 2006a. Characterization and petrologic interpretation of olivine-rich basalts at Gusev Crater, Mars. J. Geophys. Res. 111, E02S10, doi:10.1029/2005JE002477.

McSween, H.Y.,Jr., and 13 colleagues, 2006b. Alkaline volcanic rocks from the Columbia Hills, Gusev crater, Mars. J. Geophys. Res. 111, Issue E9, doi:10.1029/2006JE002698. 
Michalski, J.R., Kraft, M.D., Diedrich, T., Sharp, T.G., Christensen, P.R., 2003. Thermal emission spectroscopy of the silica polymorphs and considerations for remote sensing of Mars, Geophys. Res. Lett. 30(19), 2008, doi:10.1029/2003GL018354.

Milliken, R.E., Swayze, G., Arvidson, R.E., Bishop, J.L., Clark, R.N., Ehlmann, B.L., Grotzinger, J., Morris, R.V., Murchie, S.L., Mustard, J.F., Weitz, C.M., CRISM Science Team, 2008. Spectral Evidence for Sedimentary Silica on Mars. Lunar Planet. Sci. XXXIX. Abstract 1391.

Morris, R.V., Graff, T.G., Mertzman, S.A., Lane, M.D., Christensen, P.R., 2003. Palagonitic (not andesitic) Mars: Evidence from thermal emission and VNIR spectra of palagonitic alteration rinds on basaltic rock, paper presented at Sixth International Conference on Mars, Calif. Inst. of Technol., Pasadena.

Morris, R.V., and 18 coauthors, 2006. Mössbauer mineralogy of rock, soil, and dust at Gusev crater, Mars: Spirit's journey through weakly altered olivine basalt on the plains and pervasively altered basalt in the Columbia Hills. J. Geophys. Res. 111, E2, doi:10.1029/2005JE002584.

Mustard, J.F., Poulet, F., Gendrin, A., Bibring, J.-P., Yangevin, Y., Gondet, B., Mangold, N., Bellucci, G., Altieri, F., 2005. Olivine and pyroxene diversity in the crust of Mars. Science 307, 1594-1597. 
Ockert-Bell, M.E., Bell III, J.F., Pollack, J. B., McKay, C. P., Forget, F., 1997. Absorption and scattering properties of the Martian dust in the solar wavelengths. J. Geophys. Res. 102, E4, 9039-9050.

Palluconi, F.D., Kieffer, H.H, 1981. Thermal inertia mapping of Mars from $60^{\circ} \mathrm{S}$ to $60^{\circ} \mathrm{N}$. Icarus $45,415-426$.

Poulet, F., Cuzzi, J.N., Cruikshank, D.P., Roush T., Dalle Ore, C.M., 2002. Comparison between the Shkuratov and Hapke Scattering Theories for Solid Planetary Surfaces: Application to the Surface Composition of Two Centaurs. Icarus 160, 313-324.

Poulet, F., Erard, S., 2004. Nonlinear spectral mixing: Quantitative analysis of laboratory mineral mixtures. J. Geophys. Res. 109(E2), doi:10.1029/2003JE002179.

Poulet, F., Bibring, J.-P., Mustard, J.F., Gendrin, A., Mangold, N., Langevin, Y., Arvidson, R.E., Gondet, B., Gomez, C., 2005. Phyllosilicates on Mars and implications for early martian climate. Nature 438, 623-627.

Poulet, F., Gomez, C., Bibring J.-P., Langevin, Y., Gondet, B., Pinet, P., Belluci, G., Mustard, J.F., OMEGA team, 2007. Martian surface mineralogy from OMEGA/MEx: Global mineral maps. J. Geophys. Res. 112, E08S02, doi:10.1029/2006JE002840.

Poulet, F., Arvidson, R.E., Gomez, C., Morris, R.V., Bibring, J.-P., Langevin, Y., Gondet, B., Griffes, J., 2008. Mineralogy of Terra Meridiani and Western Arabia Terra from OMEGA/MEx and Implications for their Formation. Icarus 195, 106-130. 
Press, W.H., Teukolsky, S.A., Vetterling, W.T., Flannery, B.P., 2002. Numerical Recipes in $\mathrm{C}++$. Cambridge: Cambridge Univ. Press.

Rogers, A.D., Christensen, P.R. 2003, Age relationship of basaltic and andesitic surface compositions on Mars: Analysis of high-resolution TES observations of the northern hemisphere, J. Geophys. Res., doi:10.1029/2002JE001913.

Rogers, A.D., Christensen, P.R. 2007, Surface mineralogy of Martian low-albedo regions from MGS-TES data: Implications for upper crustal evolution and surface alteration, J. Geophys. Res., doi:10.1029/2006JE002727.

Roush, T.L., Esposito, F., Rossman, G.R., Colangeli, L., 2007. Estimated optical constants of gypsum in the regions of weak absorptions: Application of scattering theories and comparisons to independent measurements. J. Geophys. Res. 112, doi:10.1029/2007JE002920.

Ruff, S.W., 2004. Spectral evidence for zeolite in the dust on Mars. Icarus, 168(1), 131- 143.

Schade, U., Wäsch, R., Moroz, L., 2004. Near-infrared reflectance spectroscopy of Ca-rich clinopyroxenes and prospects for remote spectral characterization of planetary surfaces. Icarus $168,80-92$.

Shkuratov, Y., Starukhina, L., Hoffmann, H., Arnold G. 1999. A model of spectral albedo of particulate surfaces: Implications for optical properties of the Moon. Icarus 137, 235-246. 
Singer, R.B., 1981. Near-infrared spectral reflectance of mineral mixtures: Systematic combinations of pyroxenes, olivine, and iron oxides. J. Geophys. Res., 86(B9), 7967- 7982.

Sunshine, J.M., Pieters, C.M., Pratt, S., 1990. Deconvolution of mineral absorption bands: An improved approach. J. Geophys. Res. 95, 6955-6966.

Tomasko, M. G., Doose, L. R., Lemmon, M., Smith, P. H., Wegryn E., 1999. Properties of dust in the Martian atmosphere from the Imager on Mars Pathfinder. J. Geophys. Res., 104, E4, 8987-9008.

Treiman, A.H., 1995. SNC: Multiple source areas for martian meteorites. J. Geophys. Res. $100,5329-5340$.

Vincendon, M., Langevin, Y., Poulet, F., Bibring, J.-P., Gondet, B., 2007a. Recovery of surface reflectance spectra and evaluation of the optical depth of aerosols in the near-IR using a Monte-Carlo approach: Application to the OMEGA observations of high latitude regions of Mars. J. Geophys. Res., 112, E08S13.

Vincendon, M., Langevin, Y., Poulet, F., Bibring, J.-P., Gondet, B., 2007b. Retrieval of surface Lambert albedos and aerosols optical depths using OMEGA near-IR EPF observations of Mars. Lunar Planet. Sci. XXXVIII. Abstract 1650.

Wyatt, M.B., McSween, H.Y., 2002. Spectral evidence for weathered basalt as an alternative to andesite in the northern lowlands of Mars. Nature 417, 263- 266. 
Table 1. Spectral Library. Minerals are from different libraries (RELAB-Brown, SPECLIBJPL, USGS) with the following exception of olivine fayalite and Martian dust. Bold text designates end-members that comprise the minerals predominantly used in the fitting procedure. They define the so-called skeleton library. Analytical techniques are indicated when available.

Name group

Clinopyroxene

Feldspar

Olivine

Oxides

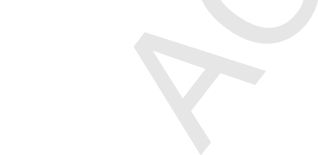

Martian dust
Albite

Forsterite

Fayalite

End-member

Diopside (HCP)

Augite

Pigeonite (LCP)

Labradorite

Magnetite

Ilmenite

Dust
Reference

(library name, sample name, other information when available) $)^{\S}$

RELAB, PP-CMP-027

High-calcium pyroxene from 1801 volcanic bomb for "soil" mixture experiment

WO46, ENS46, FS9 from microprobe analyses

USGS, NMNH120049

WO34, ENS45, FS21 from XRD analyses

RELAB, PP-EAC-042

Low-calcium pyroxene from microprobes, wet chemistry, and XRF

SPECLIB, ts02b

$\mathrm{Na}_{0.34}, \mathrm{~K}_{0.01}, \mathrm{Ca}_{0.65}, \mathrm{Si}_{2.35}, \mathrm{Al}_{1.65}, \mathrm{O}_{8}$ from XRD

RELAB, PA-CMP-005

RELAB, PO-CMP-032

Fo90

collected and analyzed by B. Platevoet

Fa99 from microprobe analyses

USGS, HS78

$\mathrm{Fe}_{3} \mathrm{O}_{4}$ from XRD

USGS, HS231

$\mathrm{FeTiO}_{3}$ from XRD

${ }^{\S}$ RELAB: Reflectance Experiment Laboratory; ASTER-SPECLIB : Advanced Spaceborne Thermal Emission and Reflection Radiometer-Spectral library; USGS: US Geological Survey. 
Table 2. Optimized parameters for the modeling of the DCT spectrum in using two kinds of HCP mineral (see Fig. 3). The values of the ratio $\mathrm{LCP} /(\mathrm{LCP}+\mathrm{HCP})$ are indicated.

Diopside

Augite

$$
\text { Grain size ( } \mu \mathrm{m}) \quad \text { Abundance }(\%) \quad \text { Grain size }(\mu \mathrm{m}) \quad \text { Abundance (\%) }
$$

\begin{tabular}{lllll} 
Dust & 5 & 0 & 5 & 0 \\
Olivine & - & 0 & - & 0 \\
HCP & 150 & 33 & 100 & 27 \\
LCP & 60 & 18 & 75 & 16 \\
PLG & 150 & 49 & 70 & 53 \\
RMS & \multicolumn{2}{c}{$0.21 \%$} & & $0.20 \%$ \\
LCP/(LCP+HCP) & & 0.35 & & 0.37
\end{tabular}

Table 3. Average modeled mineral abundances and grain size ranges for OMEGA spectra over the DCT unit compared to TES results (Rogers and Christensen, 2007). The RMS value is $0.25+/-0.03 \%$.

\section{TES OMEGA}

Abundance (\%)

\begin{tabular}{|c|c|}
\hline Abundance $(\%)$ & Grain size $(\mu \mathrm{m})$ \\
\hline $29+/-4$ & $230+/-150$ \\
\hline $11+/-4$ & $80+/-30$ \\
\hline $49+/-7$ & $100+/-30$ \\
\hline$<5$ & $100^{\$}$ \\
\hline $7+/-4$ (dust) & $5^{\$}$ \\
\hline $0.26+$ & \\
\hline
\end{tabular}

${ }^{(}$Neutral components correspond to the minerals that are spectrally featureless in the NIR.

${ }^{\$}$ Fixed (see text). 


\section{Figure captions}

Fig 1. (A) Synthetic spectra of the major end-members used in the modeling. (B) Synthetic spectra of the LCP and HCP minerals for two different grain sizes. (C) Same as B but for forsterite and three grain sizes $(10,100$ and $1000 \mu \mathrm{m})$. (D) Same as $\mathrm{C}$ but for fayalite.

Fig. 2. Effects of the admixtures. (A) Synthetic spectra of intimate mixtures of HCP mixed with varying concentrations of plagioclase (from 0 to $80 \%$ by step of $20 \%$ ). A spectrum extracted from the mafic-rich DCT terrains is shown in red for comparison. (B) Same as (A) but with LCP instead of HCP. (C) Same as (A) but with olivine (Fo90) instead of HCP. (D) Synthetic spectra of three mixings of olivine (Fo90) with HCP in different proportions $(0,20,40)$. The grain size is $50 \mu \mathrm{m}$ for each mineral.

Fig. 3. Modeling of a spectrum extracted from the DCT unit of Terra Meridiani. (A) Spectra of the major end-members used in the fit procedures. (B) OMEGA spectrum (black line) compared to two best fit models (red and blue lines) and a model-derived spectrum (green line) for which the LCP component was excluded. The best fits in red and blue includes diopside and augite respectively as the HCP end-member. The values of the RMS are indicated.

Fig. 4. Average modal abundances inferred from two simulations of 3000 spectra of DCT terrains. The two simulations differ in the HCP end-members (diamond: diopside, triangle: augite). The average RMS values are the same (0.27\%). 
Fig. 5. Sensitivity to the grain size. (A) The OMEGA spectrum (black line) is compared to three models. The best fit (red line) is obtained by assuming all the parameters free (see Table 2 for final results) and was already shown on Fig. 3. If the grain size is forced to be 100 (blue spectrum) or $200 \mu \mathrm{m}$ (green spectrum), the fits are slightly degraded. (B) The abundances of three major minerals correspond to the simulations shown in (A).

Fig. 6. Effect of the grain size of plagioclase. (A) Data spectrum compared to four modelderived spectra for which the size of plagioclase grains is fixed to $10 \mu \mathrm{m}$ (red spectrum), 100 $\mu \mathrm{m}$ (orange), 500 (cyan), and $1000 \mu \mathrm{m}$ (green). The blue spectrum indicates the best fit when all the parameters including the plagioclase grain size are free. In this case, the grain size of plagioclase is a free parameter. (B) Abundance of the different minerals for the five fitting procedures shown in (A). RMS is considered to be acceptable when it is smaller than $0.30 \%$.

Fig. 7. Effect of the input values on the final abundances and grain sizes. The results of two simulations using different initial conditions are shown. For each run (right and left), from top to bottom, the HCP, LCP and PLG abundances and grain sizes are plotted versus the pyroxene band depth as defined in Poulet et al. (2007). The horizontal dashed red lines indicate the input value of each parameter. Note that the final average abundance of dust (respectively olivine) is equal to $6+/-3 \%$ (resp. $<4 \%$ ) for the simulation 1 , and $7+/-4 \%$ (resp. $<4 \%$ ) for simulation 2 . The average RMS is $0.29 \%$ (resp. $0.30 \%$ ) for simulation 1 (resp. simulation 2).

Fig. 8. Ranges of values (grain size and abundances) investigated during fitting procedures vs RMS of 6 spectra representative of 6 band depths (from 1 to 6\%). The colour code is: plagioclase in red, HCP in dark blue, LCP in light blue, olivine in yellow and dust in black. 
The horizontal dashed line indicates RMS equal to $0.35 \%$, value that can be considered to be acceptable.

Fig. 9. (A) Spectra of end-members used for the fits shown in (B). The olivine is forsterite with grain size forced to be $10 \mu \mathrm{m}$. (B) Spectrum and best fits without olivine (red), with an olivine abundance forced to be 10\% (green) and 15\% (blue). Grain size and abundance are indicated for each end-member. Values in parenthesis correspond to the best fit (red spectrum) and are compared to the simulation with $10 \%$ of olivine. The arrow indicates the location where the spectrum is the most affected by the presence of olivine. (C) Same as (A) but the grain size is here forced to be $100 \mu \mathrm{m}$. (D) Spectrum and best fits without olivine (red) and with olivine at 5\% (blue).

Fig. 10. Two OMEGA observations of a dark terrain $\left(354.7^{\circ} \mathrm{E}, 2.63^{\circ} \mathrm{S}\right)$ close to the Opportunity landing site (solid lines) with similar photometric angles (nadir pointing, solar incidence angle of $\sim 50^{\circ}$ ) but different amounts of dust in the atmosphere (dustier conditions in black). Aerosol optical depths tau, interpolated at $0.926 \mu \mathrm{m}$ from Pancam measurements, are indicated (Lemmon et al., 2004; 2006). The surface spectra retrieved from these observations (dashed lines) are similar, which further validates our approach.

Fig. 11. (A) Observed OMEGA spectra (black) of three different terrains in Terra Meridiani, and associated surface spectra free of aerosol contribution (red). (B) Ratio of spectra after and before the aerosol correction.

Fig. 12. The final abundances and grain sizes for the simulation 1 shown in Fig. 7, but the spectra are here corrected of the aerosol contribution. The horizontal dashed red lines indicate 
the input value of each parameter. Note that the average abundance of dust (resp. olivine) is equal to $6+/-3 \%$ (resp. $<3 \%$ ). The average RMS is $0.29 \%$ for this simulation.

Fig. 13. Pyroxene band depth over Terra Meridiani (from Poulet et al., 2008). The white star indicates the opportunity landing site. The boundaries of different geological units from Arvidson et al. (2003) are plotted in black (E : Etched Terrains, MCT : Mantle Cratered Terrains, Ph : Hematite-bearing Plain). The red lines outline the terrains where the model is applied.

Fig. 14. Final values of the mineral abundance and grain size of the major minerals for each spectrum of a part of the DCT region shown in Fig. 13. The values are plotted versus the pyroxene band depth parameter calculated as in Poulet et al. (2007). 

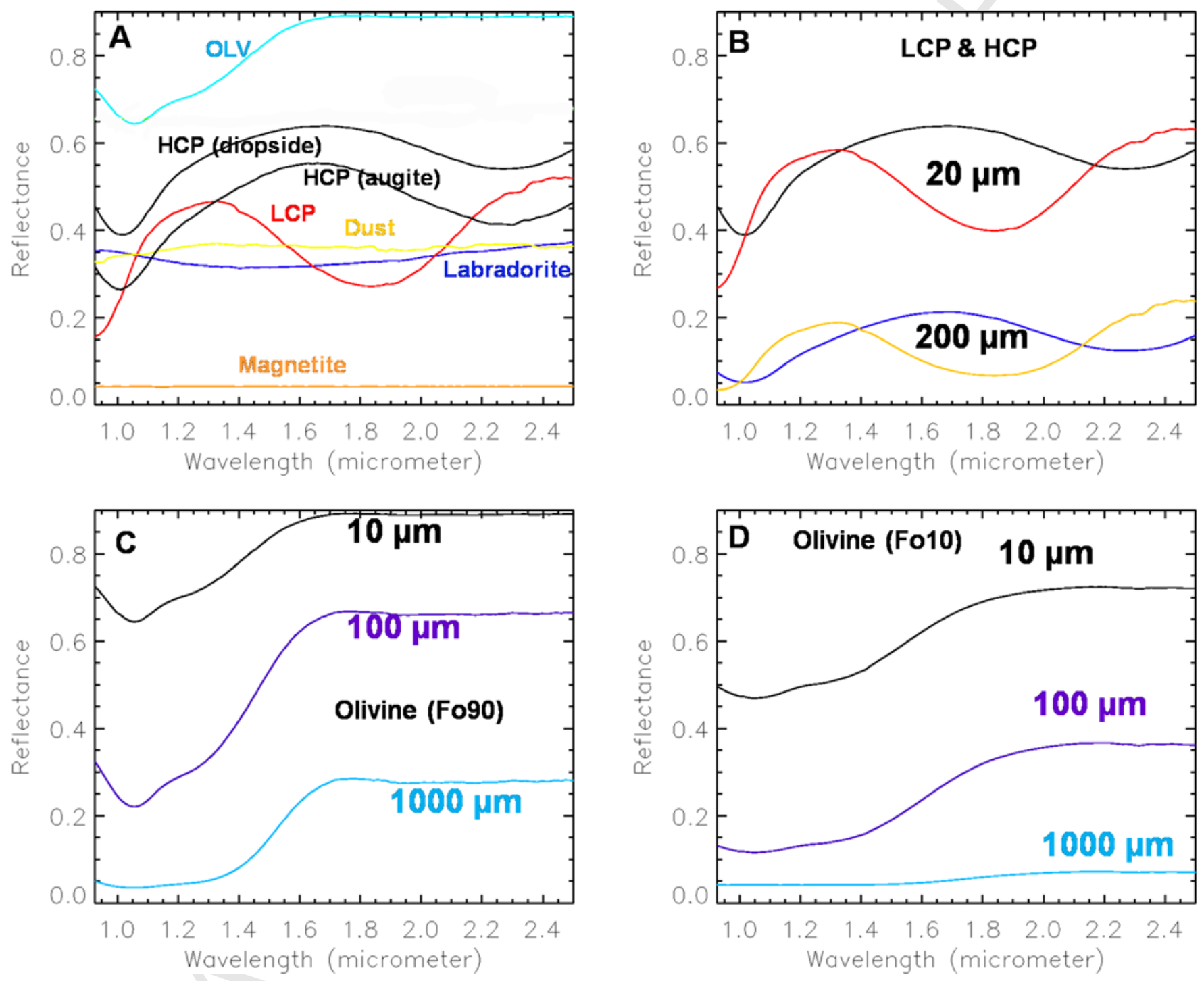

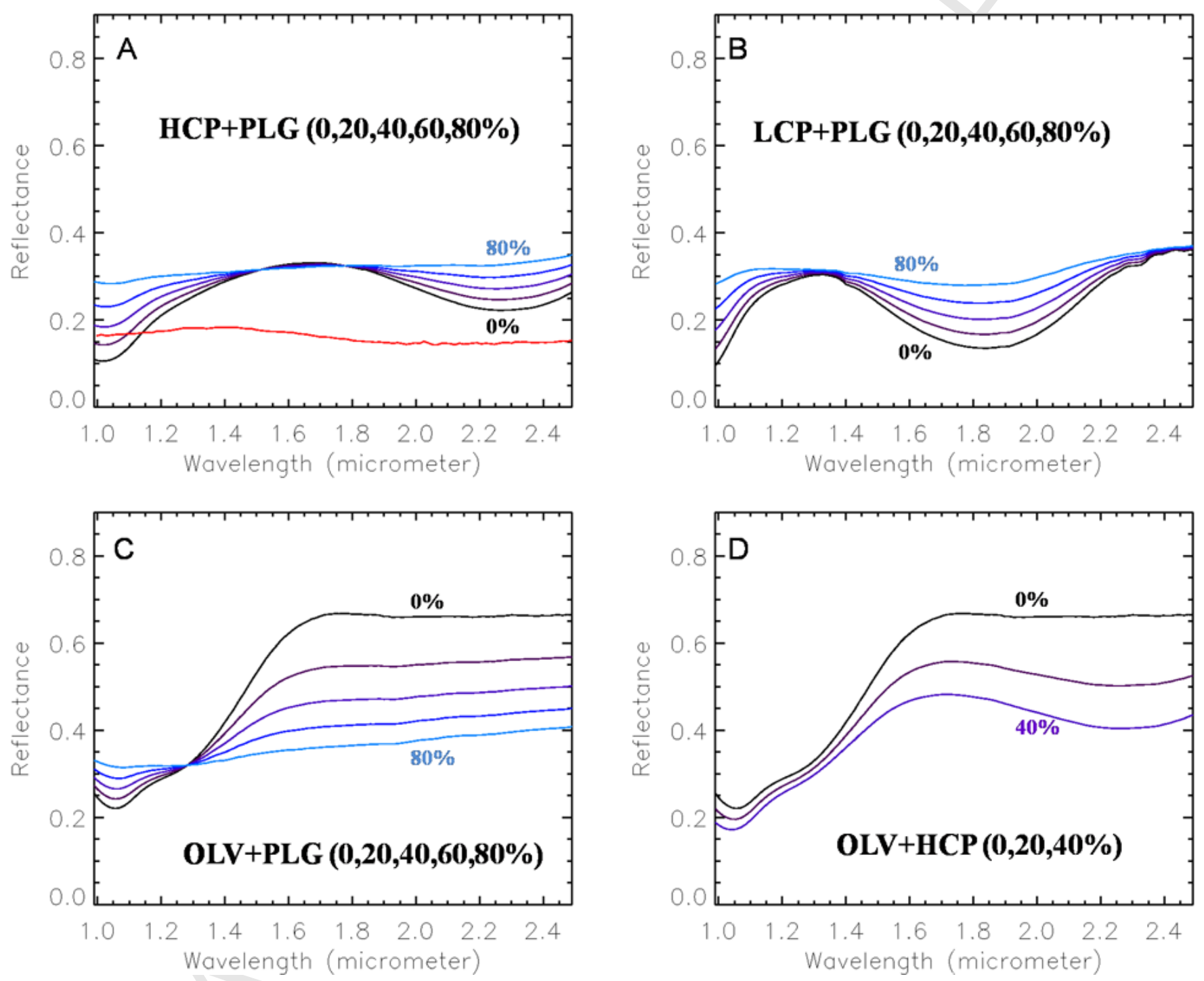

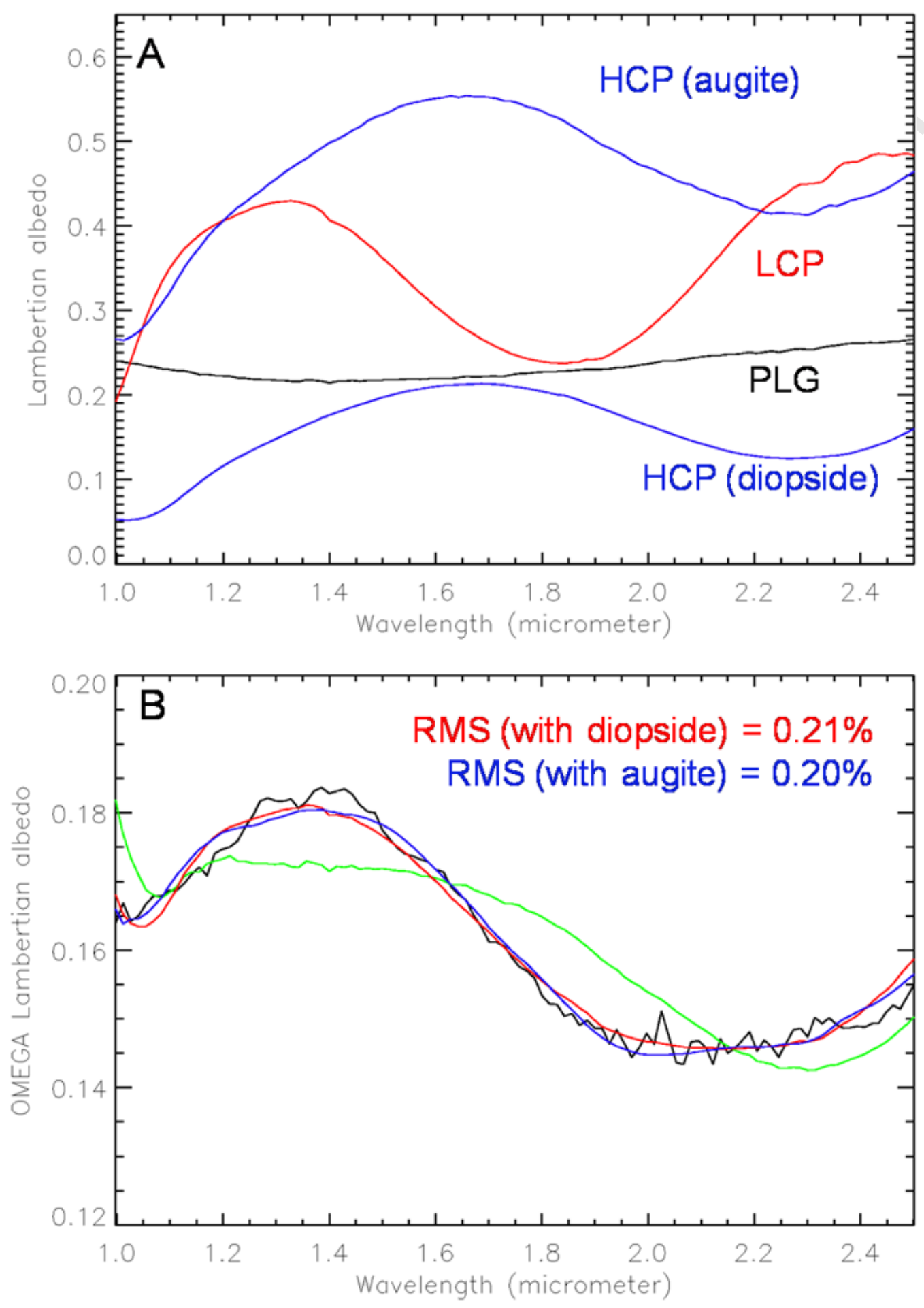


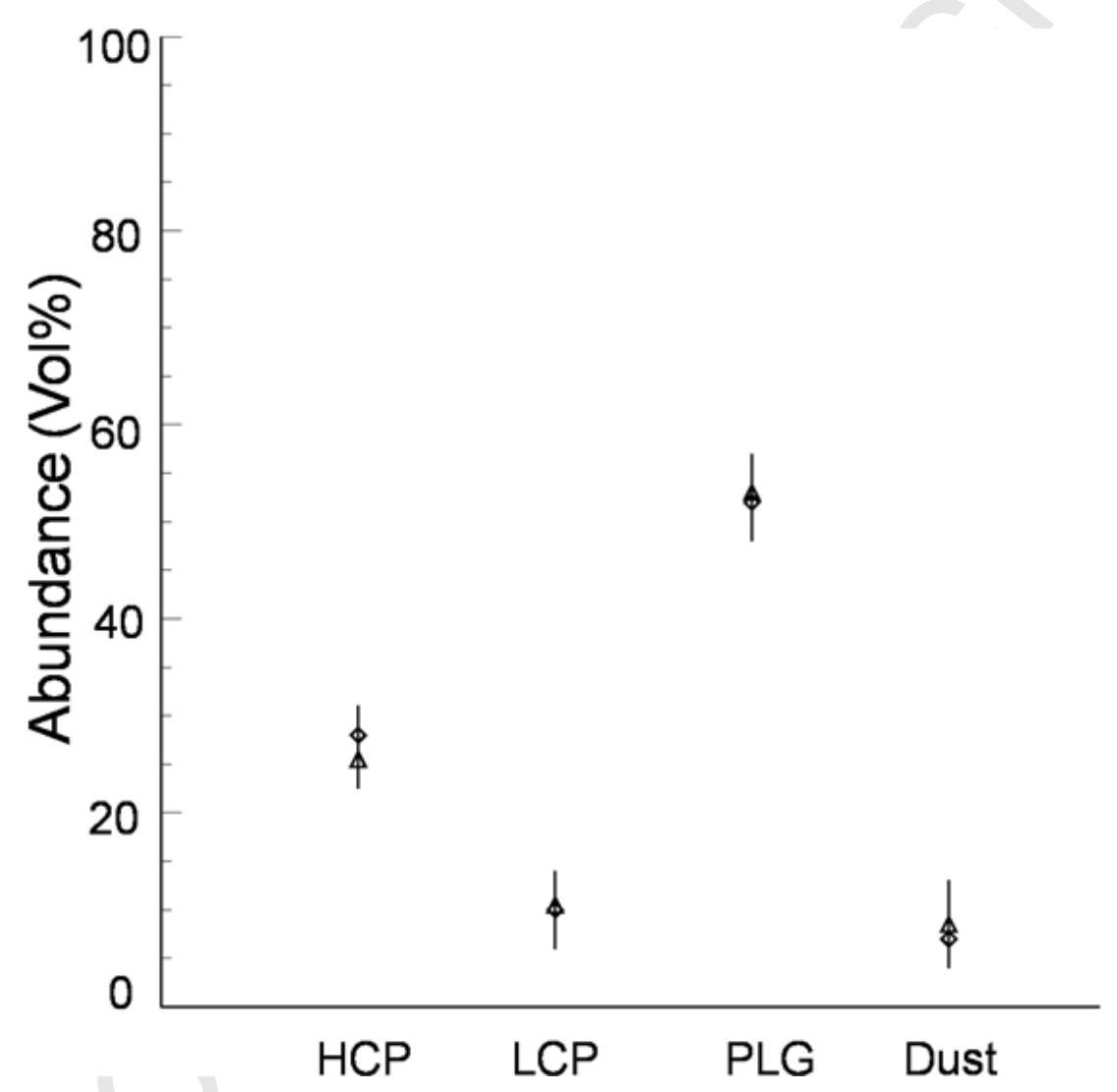



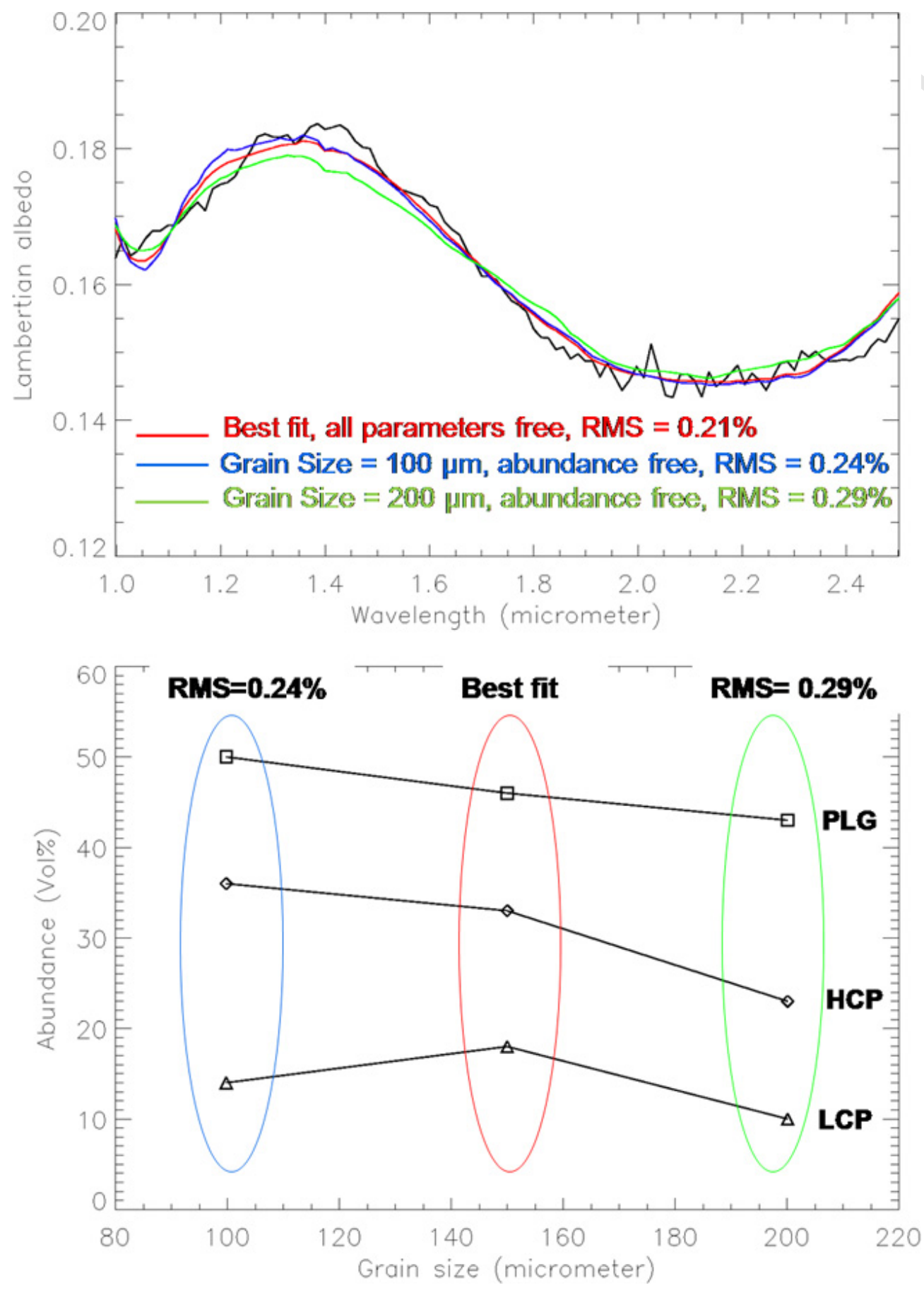

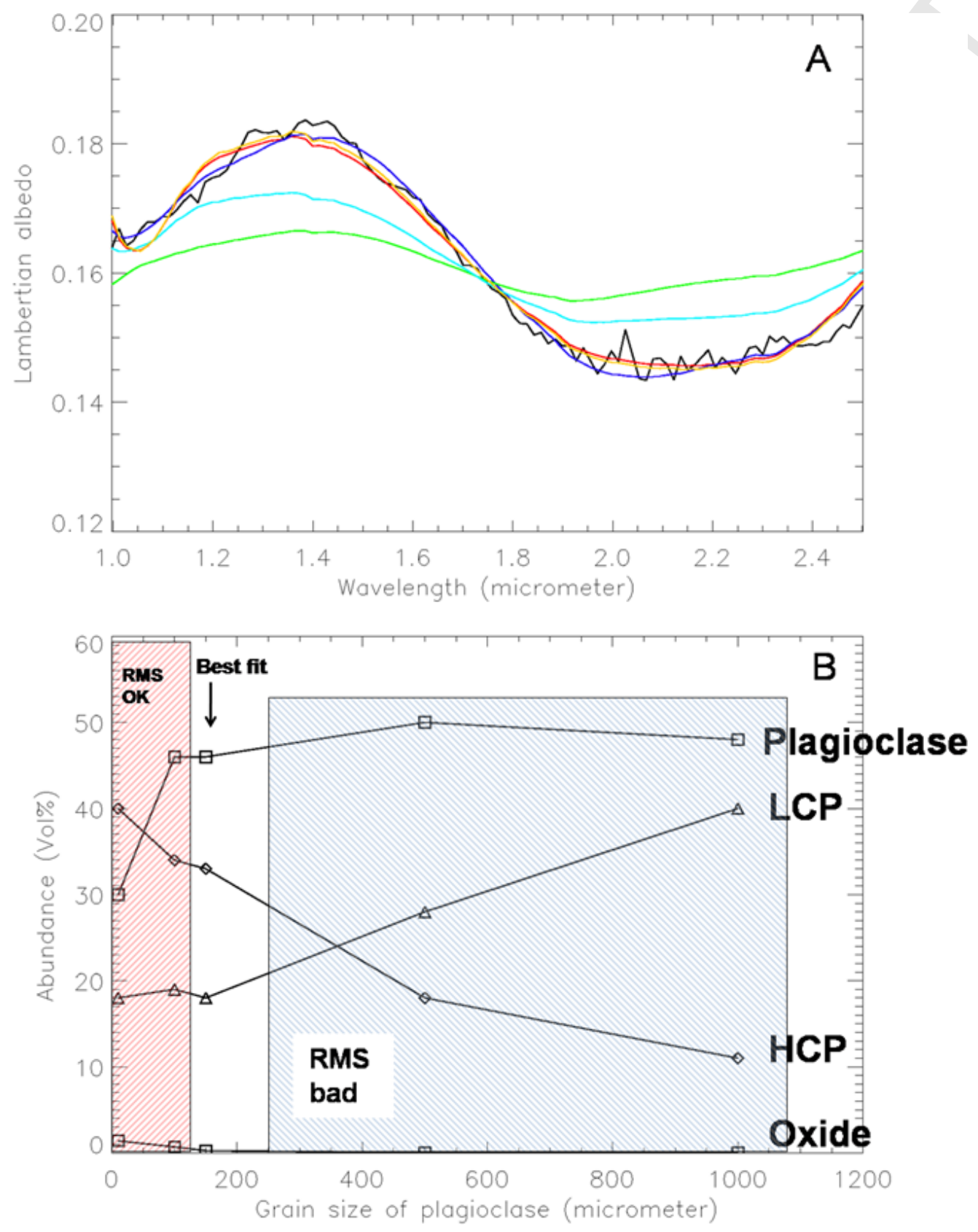

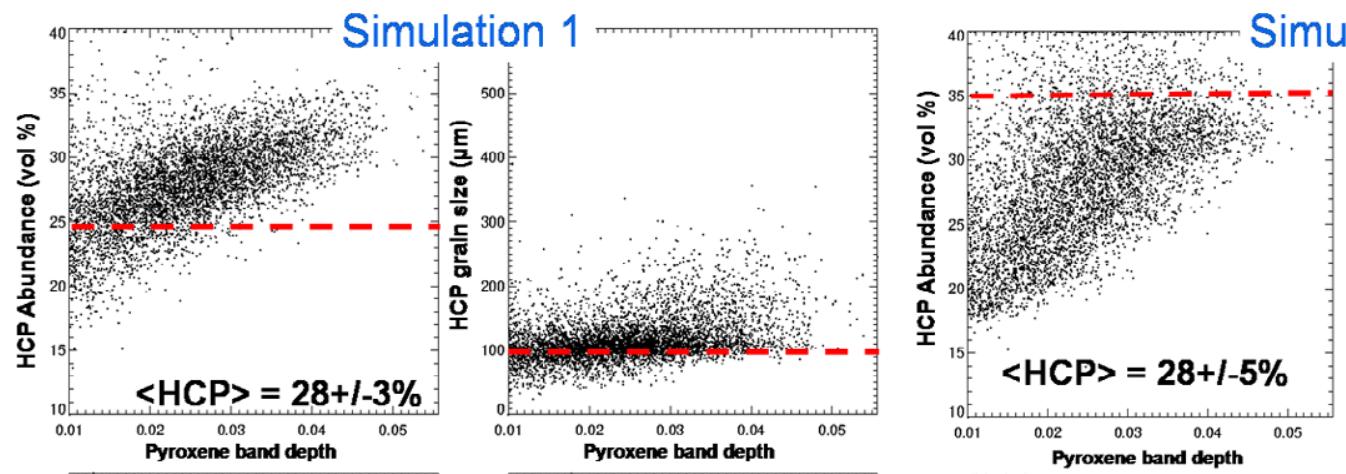

Simulation 2
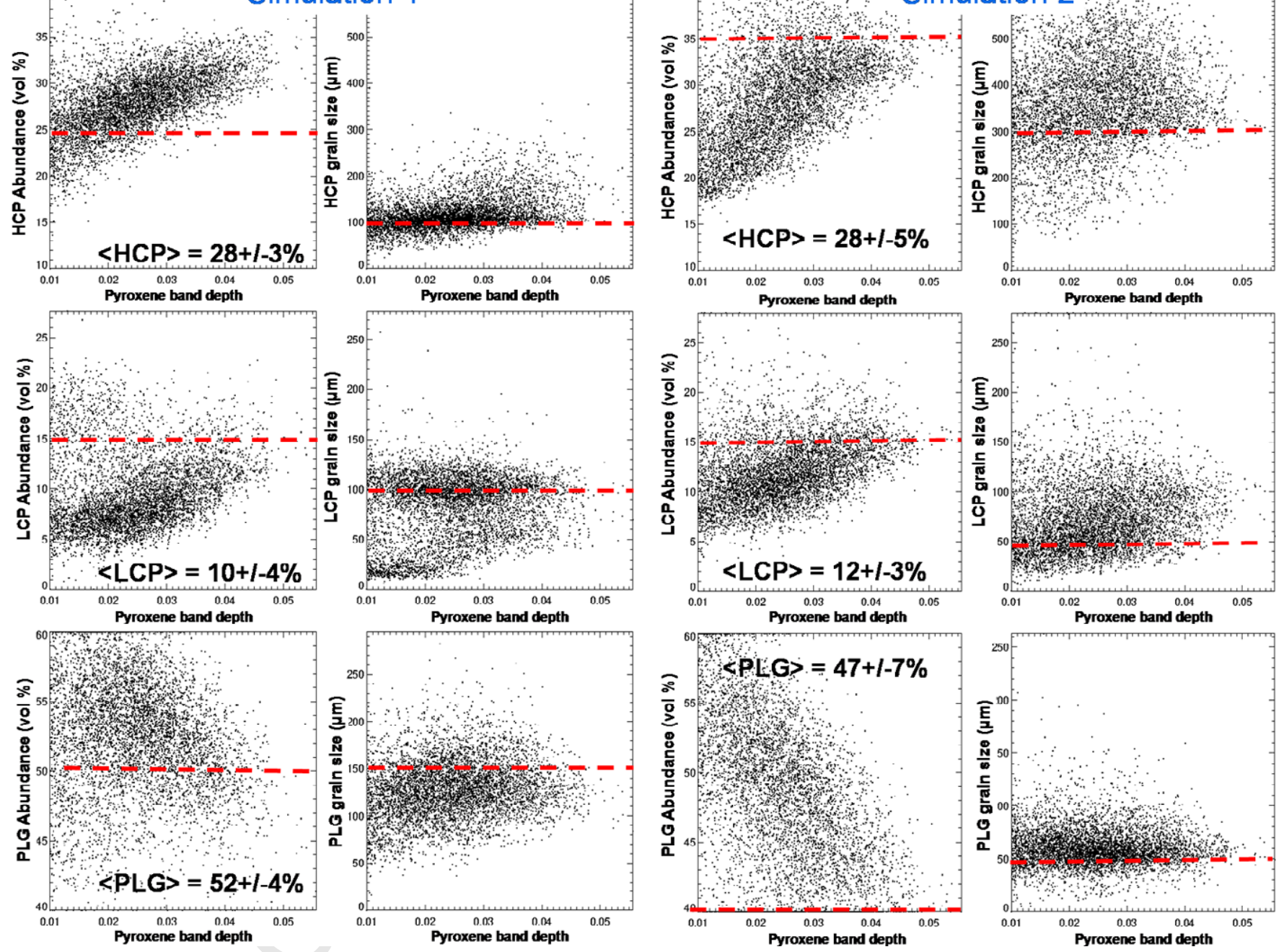

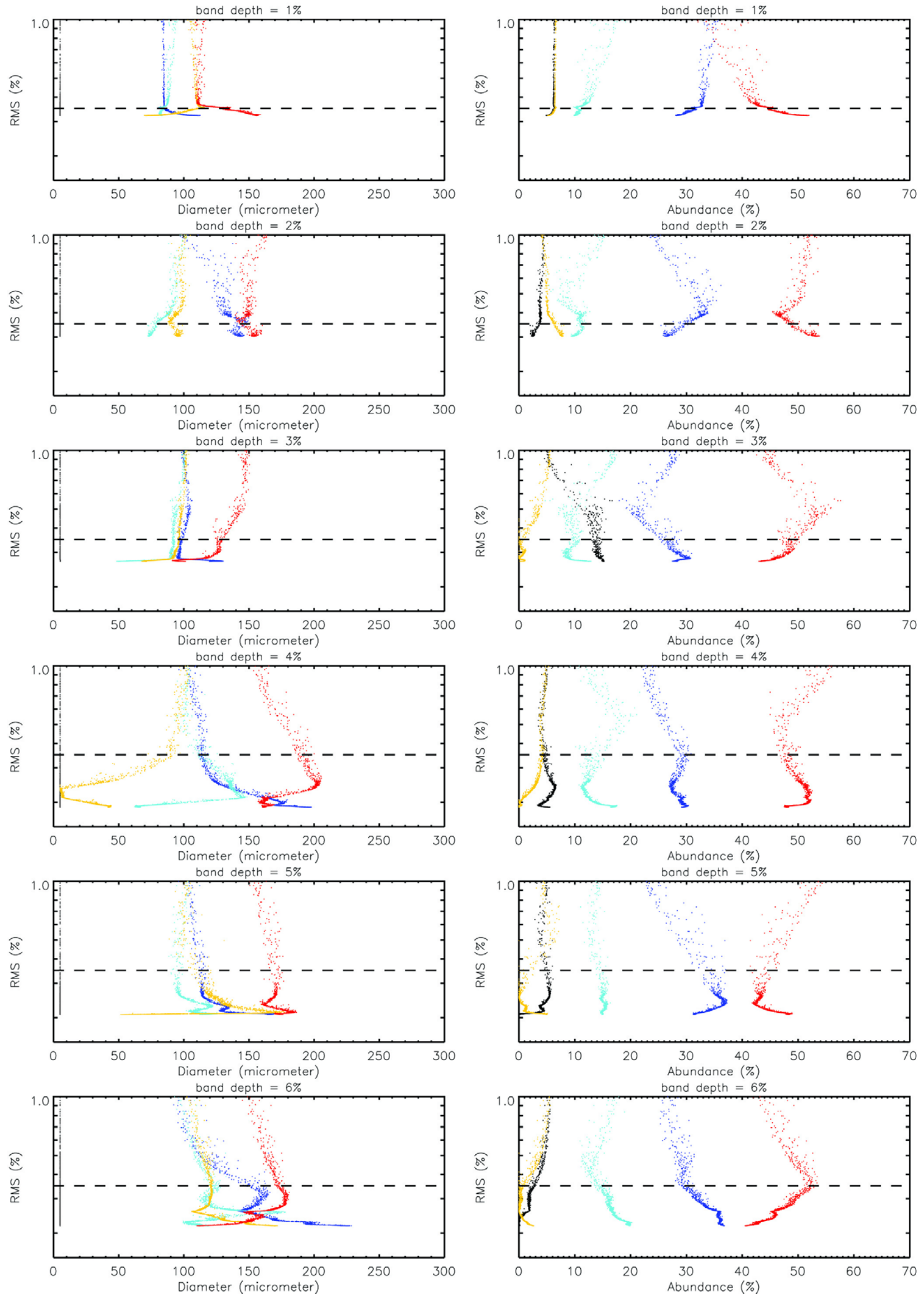

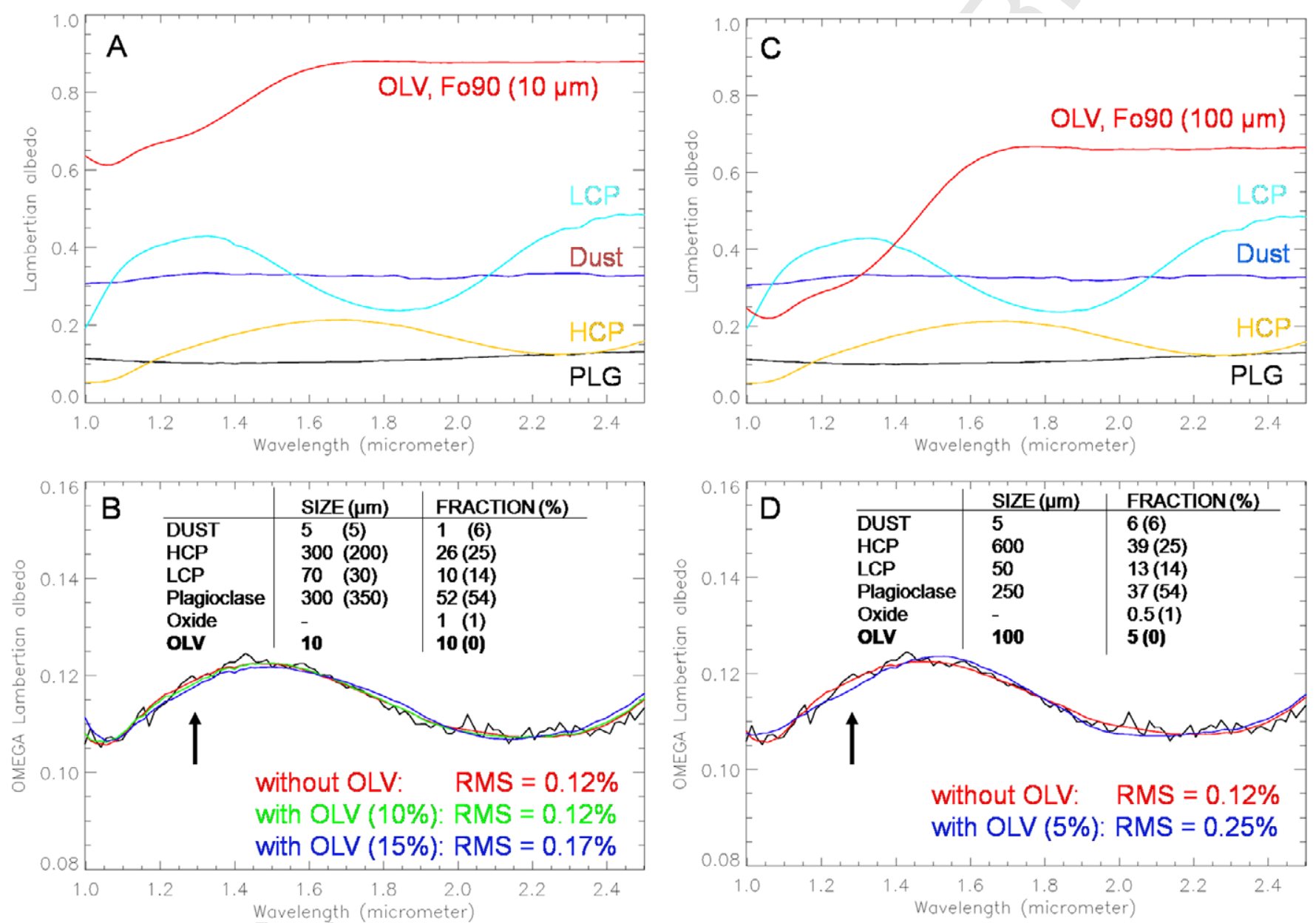


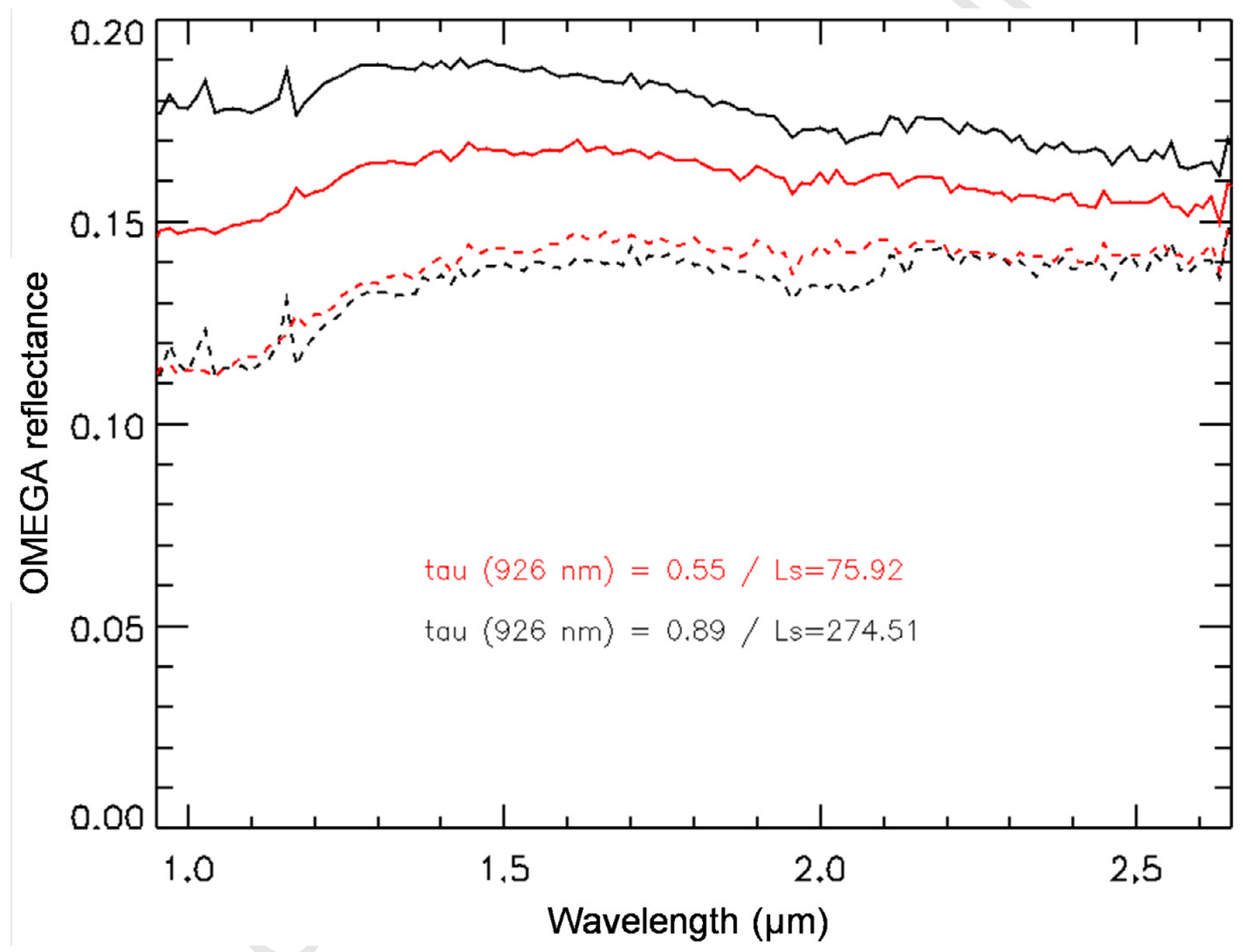




\section{ACCEPTED MANUSCRIPT}
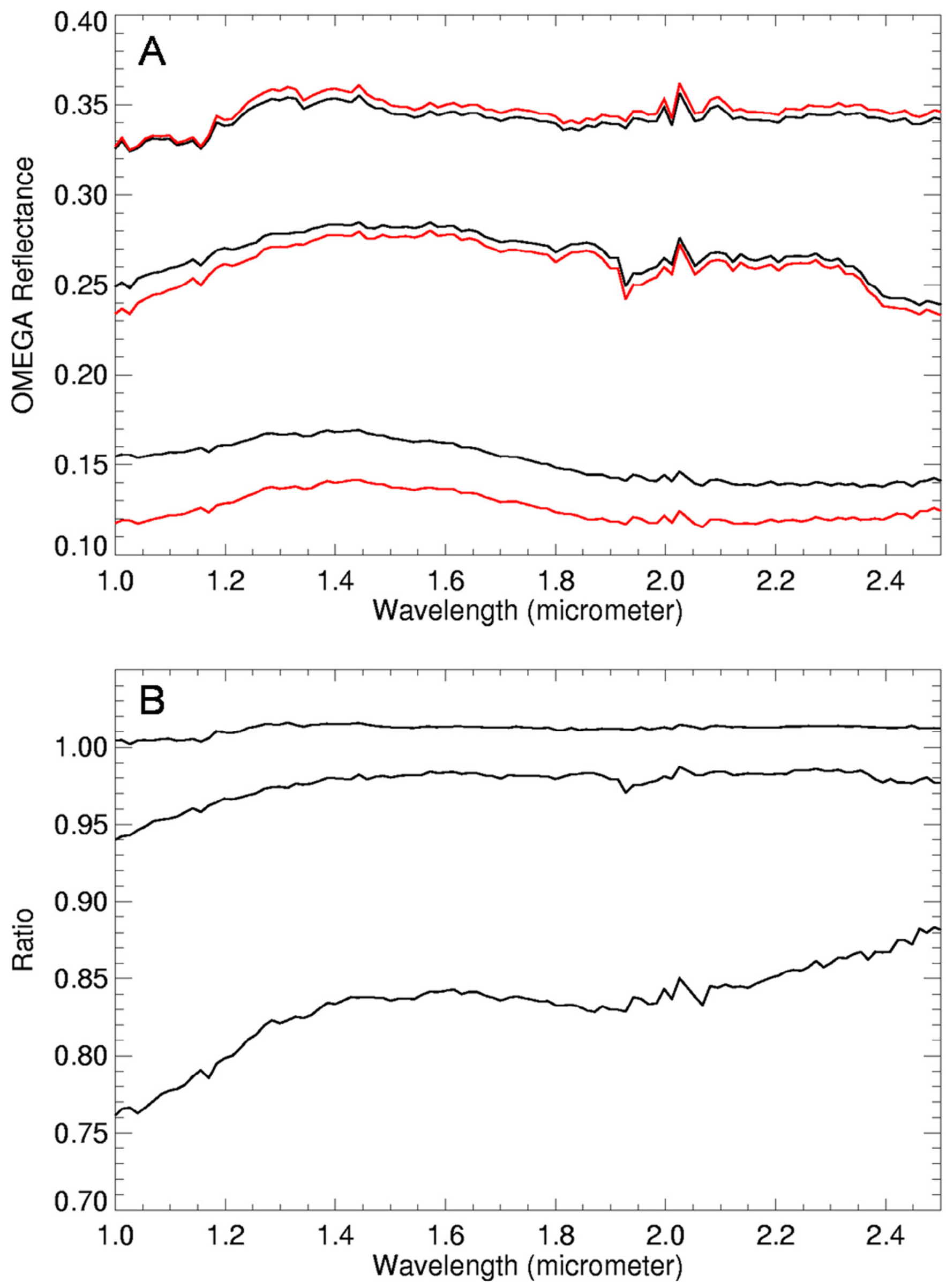

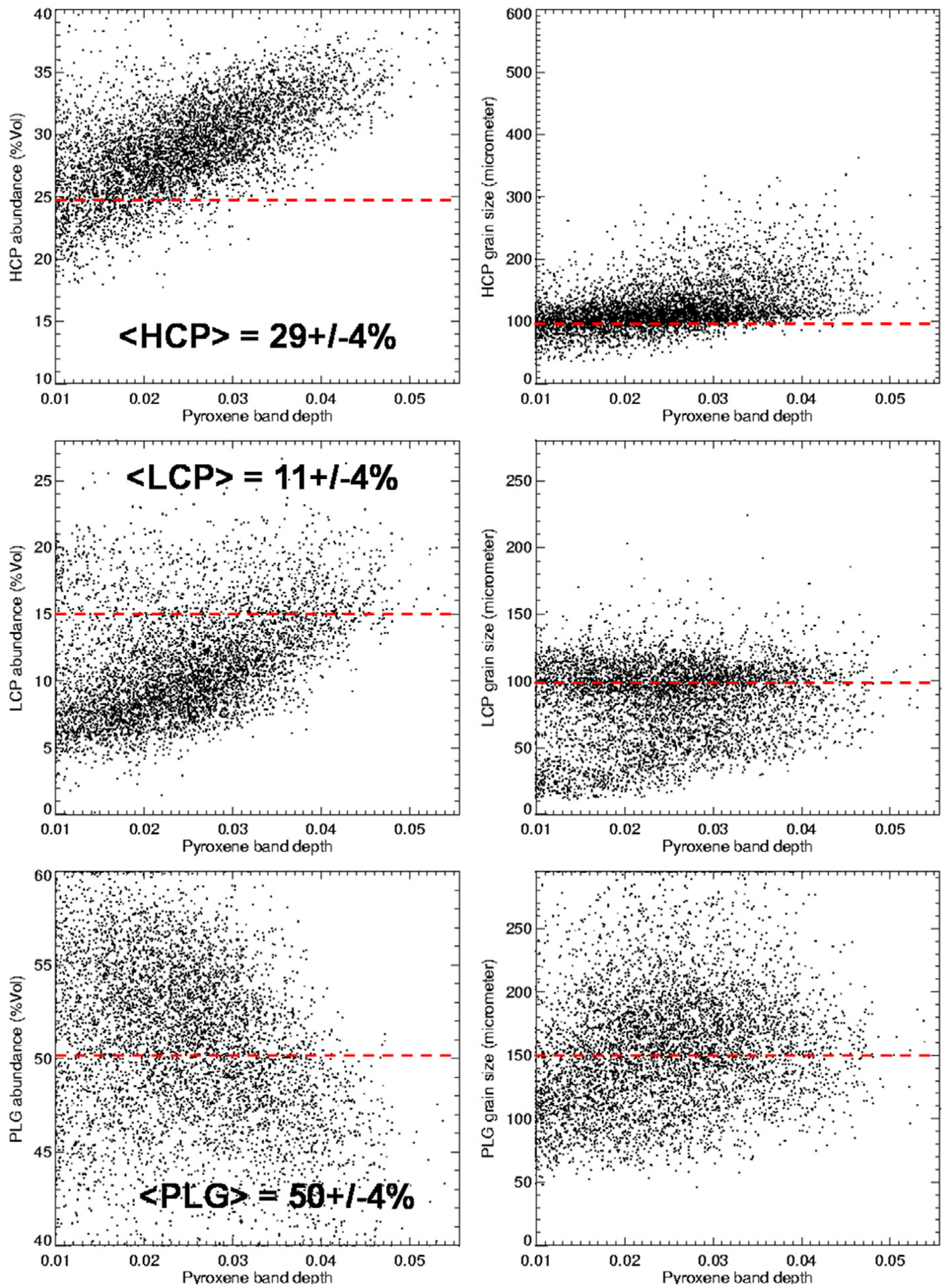


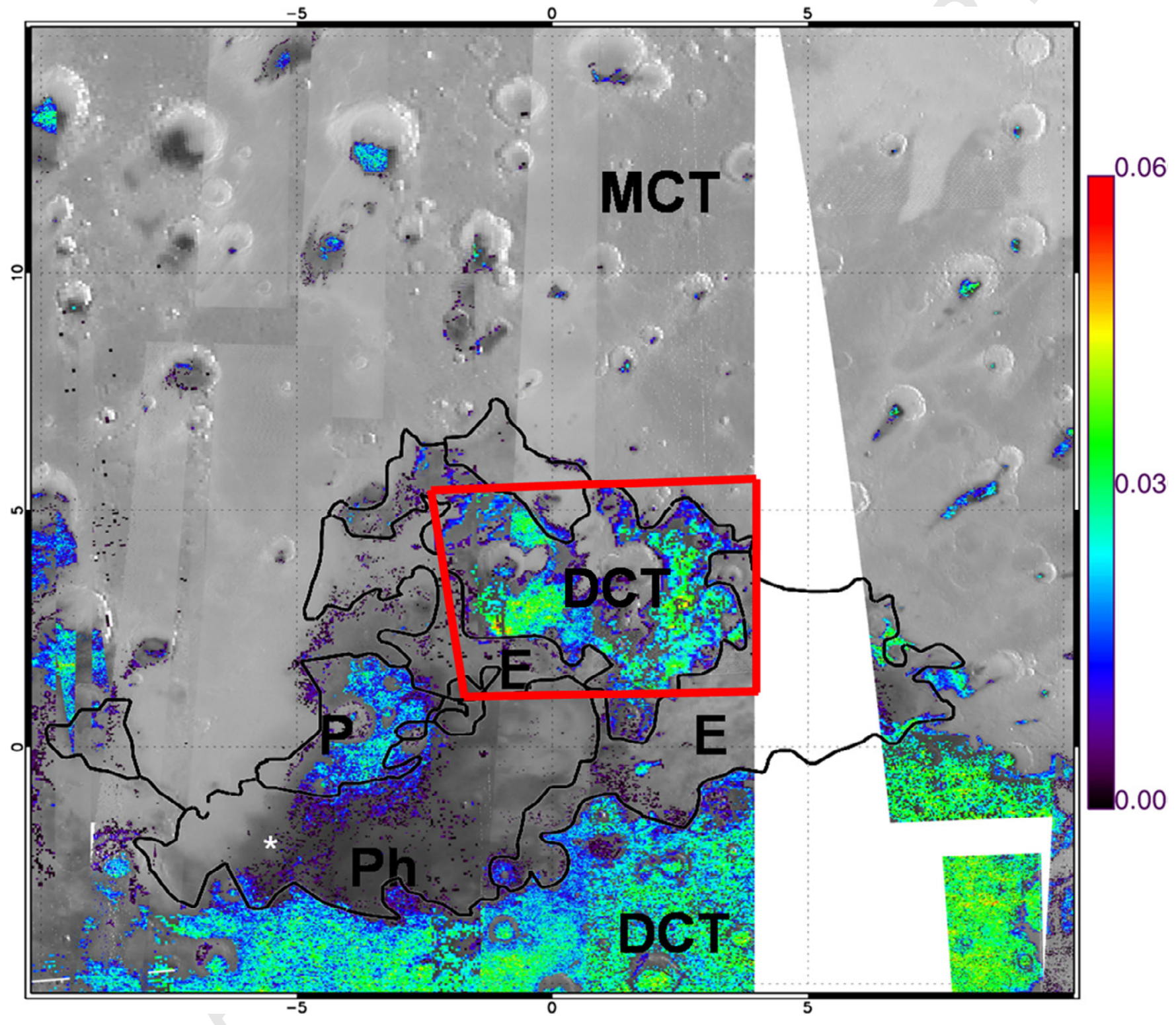



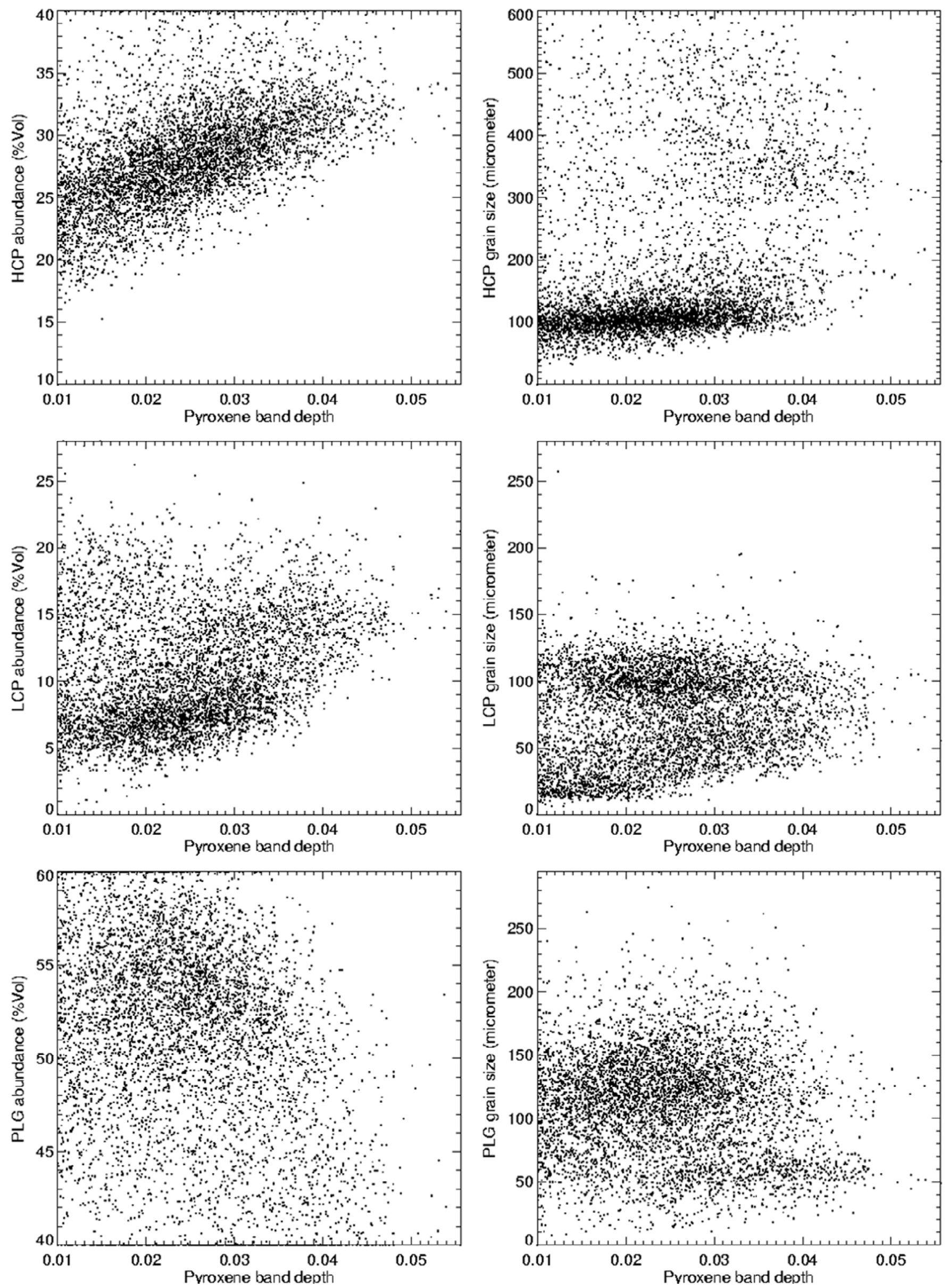